\title{
SSM/I integrated water vapor content measurements in coastal regions: A comparison with shipborne and airborne remote sensing measurements, radiosonde measurements, and NWP model retrievals
}

Cyrille Flamant and Jacques Pelon

Service d'Aéronomie/Institut Pierre Simon Laplace, Centre National de la Recherche Scientifique (CNRS), Université Pierre et Marie Curie, Paris, France

Laurence Eymard

Centre d'Etude des Environnements Terrestre et Planétaires (CETP)/Institut Pierre Simon Laplace, Centre National de la Recherche Scientifique (CNRS), Université St Quentin-Versailles, Vélizy, France

Jean Tournadre

Département d'Océanographie Spatiale Direction des Recherches Océaniques/Océanographie Spatiales, Institut Français de Recherche pour l'Exploitation de la Mer (IFREMER), Brest, France

Received 24 July 2001; revised 28 May 2002; accepted 28 May 2002; published 11 January 2003.

[1] The Special Sensor Microwave Imager (SSM/I) integrated water vapor content (IWVC) estimates in a coastal region during nonstationary cold-air outbreak conditions are analyzed using IWVC retrievals obtained from shipborne microwave radiometry (DRAKKAR), water vapor differential absorption laser remote sensing (LEANDRE 2), radiosonde measurements, and numerical weather prediction (NWP) model ALADIN of Météo-France. The study focuses on the 24 March 1998 Tramontane/Mistral event, which occurred over the Gulf of Lion (GoL) (western Mediterranean) in the framework of the flux, état de mer et télédétection en condition de fetch variable (FETCH) experiment. Comparisons of SSM/I and ALADIN IWVCs with collocated shipborne microwave radiometry, at distances from the coast between 50 and $100 \mathrm{~km}$, were carried out on a full diurnal cycle. In the morning, when moister conditions prevailed, the agreement between SSM/I (one passage) and DRAKKAR was good while the bias observed in the afternoon (three passages) was larger (i.e., $2 \mathrm{~kg} \mathrm{~m}^{-2}$ ). Reasons for this are investigated. We show that this is due to the fact that the sensitivity limit of the algorithm has been reached during very dry Mistral conditions. This bias is not explained by effects of land contamination, which is shown to remain below $0.2 \mathrm{~kg} \mathrm{~m}^{-2}$. No systematic bias was observed between ALADIN and DRAKKAR. Nevertheless, the trend observed on the DRAKKAR data between 1430 and 2030 UT was best captured by SSM/I despite the sensitivity issue. SSM/I and ALADIN IWVC estimates were also found to be in good agreement with collocated airborne lidar measurements, thereby reproducing the spatial evolution of the IWVC with the distance to the coast. INDEX TERMS: 3329 Meteorology and Atmospheric Dynamics: Mesoscale meteorology; 3360 Meteorology and Atmospheric Dynamics: Remote sensing; 3394 Meteorology and Atmospheric Dynamics: Instruments and techniques; 0360 Atmospheric Composition and Structure: Transmission and scattering of radiation; KEYWORDS: SSM/I, Lidar, microwave radiometry, integrated water vapor content, Mistral, FETCH

Citation: Flamant, C., J. Pelon, L. Eymard, and J. Tournadre, SSM/I integrated water vapor content measurements in coastal regions: A comparison with shipborne and airborne remote sensing measurements, radiosonde measurements, and NWP model retrievals, J. Geophys. Res., 108(C3), 8056, doi:10.1029/2001JC001068, 2003.

\section{Introduction}

[2] In the past decade, the parameterization of moisture exchanges between the Earth's surface and the atmosphere has emerged as a major source of improvement for numer-

Copyright 2003 by the American Geophysical Union. 0148-0227/03/2001JC001068\$09.00 ical models of the atmosphere. Because these exchanges partly control the atmospheric boundary layer (ABL) growth and are, in turn, modulated by the ABL structure, modeling the temporal and spatial variations humidity transfers through the $\mathrm{ABL}$ is of prime importance to establishing the Earth's energy budget and essential for addressing fundamental issues dealing with the Earth's climate. 
[3] Accurate global monitoring of the distribution of water vapor in the atmosphere is essential for weather forecasting and climate studies and can readily be obtained in an integrated form (i.e., integrated water vapor content (IWVC)) over the oceans from the Special Sensor Microwave Imager (SSM/I) [Alishouse et al., 1990] and over land from the Polarization and Directionality of Earth Reflectances (POLDER) sensor [Vesperini et al., 1999]. While the assimilation of SSM/I-derived IWVC in numerical weather prediction (NWP) models has yet to prove its efficiency for improving notably humidity forecasts [Gérard and Saunders, 1999; Gérard and Pailleux, 2000], SSM/I-derived IWVCs have been shown to provide useful information for meteorological and climate research [e.g., Stephens, 1990; Jackson and Stephens, 1995]. However, These analyses have been conducted only over homogeneous water surfaces and in fully developed sea state conditions. In coastal regions, high emissivity associated with the closeby continental surfaces may seriously hamper IWVC retrievals. Furthermore, the impact of developing waves at the sea surface on IWVC retrievals in these regions remains unknown. These regions are also affected by continental cold-air outbreaks and characterized by important ocean heat and moisture losses to the atmosphere. Last, the quality of SSM/I-derived IWVC is generally assessed via comparisons with radiosonde data [Schlüssel and Emery, 1990; Jackson and Stephens, 1995; Bennartz, 1999]. When using radiosonde data, the main limitation is that the derived IWVC is generally not representative of homogeneous or stationary conditions. Another limitation of radiosondes is their global tendency to underestimate the relative humidity (RH), particularly for low temperatures [e.g., England et al., 1993; Fleming, 1998; Helten et al., 1998].

[4] This paper aims at analyzing the of SSM/I IWVC estimates in a coastal region (at distances from the coast between 50 and $100 \mathrm{~km}$ ) during a cold-air outbreak by comparing them to "quasi-instantaneous" IWVC retrievals from shipborne microwave radiometry and water vapor differential absorption laser remote sensing. The IWVC retrievals obtained with the limited area NWP model ALADIN of Météo-France are also presented and analyzed. The study focuses on the 24 March 1998 Tramontane/ Mistral event over the Gulf of Lion (GoL) (western Mediterranean) documented in the framework of the flux, etat de mer et tldtection en condition de fetch variable (FETCH) experiment [Hauser et al., 2000, 2002]. The Tramontane and the Mistral are low level, orography-induced, cold-air outbreaks over the GoL blowing offshore of Narbonne and Arles, France, respectively (Figure 1). They are frequently observed to extend several hundreds of kilometers from the coast, bringing cold and dry continental air over the warm western Mediterranean, and hence, generating intense heat air-sea exchanges. They are one of the primary cause of storms over the Mediterranean, between Italy and Balearic Islands [Trigo et al., 1999; Campins et al., 2000].

[5] On 24 March 1998, the multistage evolution of an Alpine lee cyclone over the Tyrrhenian Sea (between Sardinia and continental Italy) lead to a very nonstationary Tramontane/Mistral wind regime over the Mediterranean (the Tramontane and the Mistral being orography-induced low level jets blowing inland over the GoL) [Flamant, 2002]. To the authors' knowledge, very few studies have

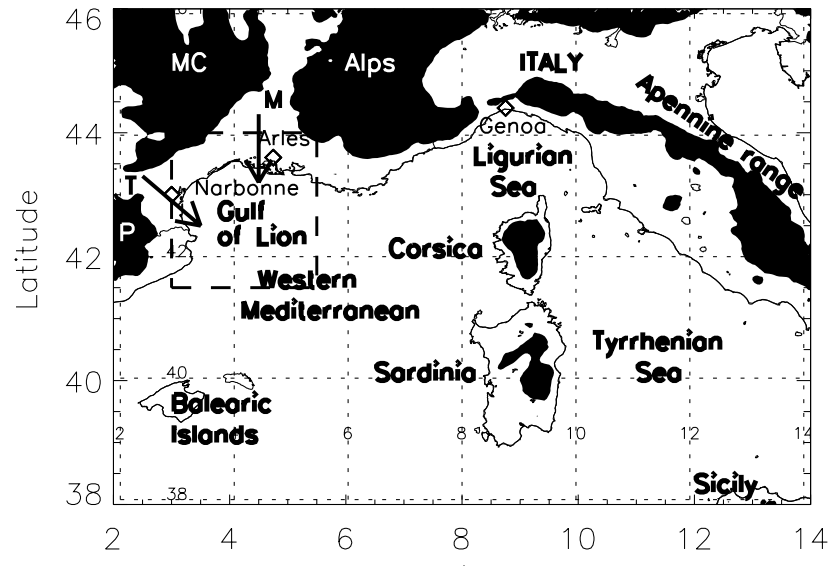

Figure 1. Presentation of the northern Mediterranean region showing the location of the geographical features referred to in this paper. Shaded areas correspond to the topography above $500 \mathrm{~m}$ : the Pyrnes (P), the Massif Central (MC), the Alps, and the Apennine range (mountains are also seen in Corsica and Sardinia). The dashed box indicates the FETCH domain within which two aircraft, a ship, and a buoy were deployed. The thick arrows indicate the climatological directions of the Mistral (M) and Tramontane (T) winds.

dealt with SSM/I IWVC retrievals in coastal regions [e.g., Bennartz, 1999]. No study has been dedicated to the analysis of SSM/I data in dry, nonstationary, coastal conditions, which push to the limit SSM/I IWVC retrieval algorithms.

[6] The paper is organized as follows. In section 2, we present an overview of synoptic conditions, and operations during the 24 March 1998 Tramontane/Mistral case documented in the framework of the FETCH. We also present the NWP model (ALADIN of Météo-France) used in this study. Section 3 discusses the IWVC retrieval characteristics for the instruments and the NWP model. In section 4, the temporal and spatial variations of the IWVC over the GoL are presented. In section 5, we compare SSM/I IWVC estimates with IWVC estimates made from the other platforms as well as three-dimensional (3-D) simulations. In section 6 , we summarize and conclude.

\section{Overview of the 24 March 1998 Case Study}

[7] In addition to the means specially deployed for FETCH, Météo-France provided daily forecasts of the meteorological situation made with the operational NWP model ALADIN. The forecasts on 24 March 1998 have been validated against buoy, ship and aircraft in situ data [Flamant, 2002]. These comparisons evidenced that the thermodynamical conditions prevailing over the GoL during the morning and afternoon airborne operations were well represented by the 1200 and 1800 UTC ALADIN forecast, respectively. In turn, the ALADIN forecasts were used by Flamant [2002] to analyze the rapid evolution of the synoptic situation on 24 March 1998. As these forecasts are also utilized in this study, we first briefly present the ALADIN model. 
[8] ALADIN is a spectral limited area model, taking its boundary conditions from the global model ARPEGE of Météo-France, which covers a domain of $2739 \times 2739 \mathrm{~km}$ (centered on France). The postprocessing horizontal resolution is approximately $0.1^{\circ} \times 0.1^{\circ}$, with 31 levels on the vertical, the highest level being at $5 \mathrm{hPa}$ and the lowest level at approximately $17 \mathrm{~m}$ above ground/sea level. The surface layer and planetary boundary layer fluxes are computed on the lowest level using a modified version of the scheme developed by Louis et al. [1981]. The 3-D var data assimilation provides two analyses per day (0000 and 1200 UTC) but no associated first guess. Forecasts are available every 3 hours, i.e., at $0000,0300,0600,0900,1200,1500,1800$, 2100 , and 2400 UTC. Three-hour integrated surface turbulent fluxes are computed from 12-hour forecasts. Additional information is given by Eymard et al. [2003]. The forecast products are temperature, humidity, and wind distributed on 15 pressure levels between 1000 and $150 \mathrm{hPa}$. Sea level pressure and surface turbulent fluxes are provided at the lowest level, i.e., $17 \mathrm{~m}$ above sea level (asl). Near surface extrapolated fields (at $10 \mathrm{~m}$ asl for the wind and $2 \mathrm{~m}$ asl for temperature and humidity) are derived assuming a neutral profile. The sea surface temperature (SST) in the model is issued from Reynolds' climatology and yields characteristic spatial and temporal scales of about $2^{\circ}$ and 8 days.

\subsection{Synoptic Situation}

[9] Based on ALADIN forecasts, Flamant [2002] has shown that the nonstationary nature of the Tramontane/ Mistral wind regime over the GoL on 24 March 1998 was controlled by the multistage evolution of an Alpine lee cyclone over the Tyrrhenian Sea (between Sardinia and continental Italy). In the early stage, the Tramontane flow prevailed over the GoL. As the low deepened, the prevailing wind regime shifted to a well established Mistral, which peaked around 1200 UTC. In the afternoon, the Mistral was progressively disrupted by a strengthening outflow coming from the Ligurian Sea in response to the deepening low over the Tyrrhenian Sea and the channeling induced by the presence of the Apennine range (Italy) and the Alps. In the evening, the Mistral was again well established over the GoL as the depression continued to deepen but moved to the southeast, reducing the influence of outflow from the Ligurian Sea on the flow over the GoL (see Figure 1 for the location of the geographical features referred to in this paper).

\subsection{Operations}

[10] The evolution of atmospheric moisture over the GoL during the 24 March 1998 Tramontane/Mistral event has been studied by means of in situ and remote sensing measurements made from an aircraft (the Avion the Recherche Atmosphérique et Télédétection (ARAT)), a ship (the Research Vessel Atalante), a buoy (the Air-Sea Interaction Spar (ASIS)) as well as several spaceborne platforms. The meteorology associated with the Tramontane/Mistral event over the GoL on 24 March 1998 as well as the related FETCH operations are described in a companion paper [Flamant, 2002] and are only briefly highlighted here.

[11] For the purpose of our research (multi-instrument approach to estimate the IWVC), we have used balloon soundings launched from the Research Vessel Atalante, DRAKKAR radiometer data acquired on the front deck of the Research Vessel Atalante, differential absorption lidar (DIAL) measurements of water vapor mixing ratio made by LEANDRE 2 [Bruneau et al., 2001a, 2001b] which was embarked on the ARAT and SSM/I estimates from 4 overpasses.

[12] Two ARAT flights were performed on 24 March 1998 (between 1014 and 1233 UTC and between 1620 and 1850 UTC) which enabled an analysis of the structure of the marine ABL (MABL) over the GoL during the established Mistral period and the period when the Mistral was perturbed by the outflow from the Ligurian Sea, respectively [Flamant, 2002]. In the following, we shall only analyze water vapor mixing ratio measurements made with LEANDRE 2 during the afternoon ARAT flights (further referred to as F03) which was conducted during a SSM/I overpass. The Research Vessel Atalante cruised all day in the GoL, in the vicinity of the moored ASIS buoy $\left(43^{\circ} \mathrm{N} / 4.25^{\circ} \mathrm{E}\right)$.

\section{IWVC Estimates From Instruments and NWP Model Forecasts}

\subsection{Balloon Soundings and Soundings Reconstructed} From ALADIN Simulations

[13] In the midlatitude regions, where the atmosphere is relatively dry, the density of moist air can be determined from sounding measurements as

$$
\rho=\frac{p q}{R T},
$$

where $p$ is the pressure, $q$ the water vapor mixing ratio, $R$ is the perfect gas constant for dry air $\left(R=461.5 \mathrm{~J} \mathrm{~K}^{-1} \mathrm{~kg}^{-1}\right)$, and $T$ is the temperature, and where we have assumed that $q$ $\ll 0.622 \mathrm{~g} \mathrm{~kg}^{-1}$. The IWVC is then the integral of (1) over the vertical.

[14] This method for estimating the IWVC has been applied to the three soundings made from the Research Vessel Atalante at 0900, 1200, and 2400 UTC. IWVCs have been retrieved up to $19.5,16$, and $20 \mathrm{~km}$ asl, respectively, from these soundings. A limitation of radiosondes is their global tendency to underestimate the RH by up to $7 \%$, particularly for low temperatures [Helten et al., 1998]. Moreover some sensors do not respond to humidity changes at temperatures lower than $-30^{\circ} \mathrm{C}$ [England et al., 1993]. Both the 0900 and 1200 UTC balloon soundings evidenced that temperatures below $-30^{\circ} \mathrm{C}$ were observed above $7 \mathrm{~km}$ asl (not shown). The contribution of the atmosphere above 7 $\mathrm{km}$ asl to the IWVC, computed as $\int_{7 \mathrm{~km}}^{15 \mathrm{~km}} \rho d z^{\prime} / \int_{0}^{15 \mathrm{~km}} \rho d z^{\prime}$, amounted to $2.5 \%$. Hence, the erratic behavior of humidity sensors at low temperatures is not expected to impact significantly the IWVC retrievals from soundings.

[15] IWVC retrievals from ALADIN were computed as the integral between the surface and $150 \mathrm{hPa}$ of moist air density profiles reconstructed from forecasts of standard meteorological fields (temperature and $\mathrm{RH}$ ). This was done over the entire FETCH domain (shown in Figure 1). The ALADIN retrieval uncertainties will be related to the forecast errors that are difficult to estimate, particularly for water vapor mixing ratio. Instead, an attempt was made to estimate these uncertainties by comparing balloon sounding measurements and model outputs extracted at the location of the Research Vessel Atalante at 0900 and 1200 UTC (Figure 2). At 0900 UTC, fair agreement was found between ALADIN 
(a)

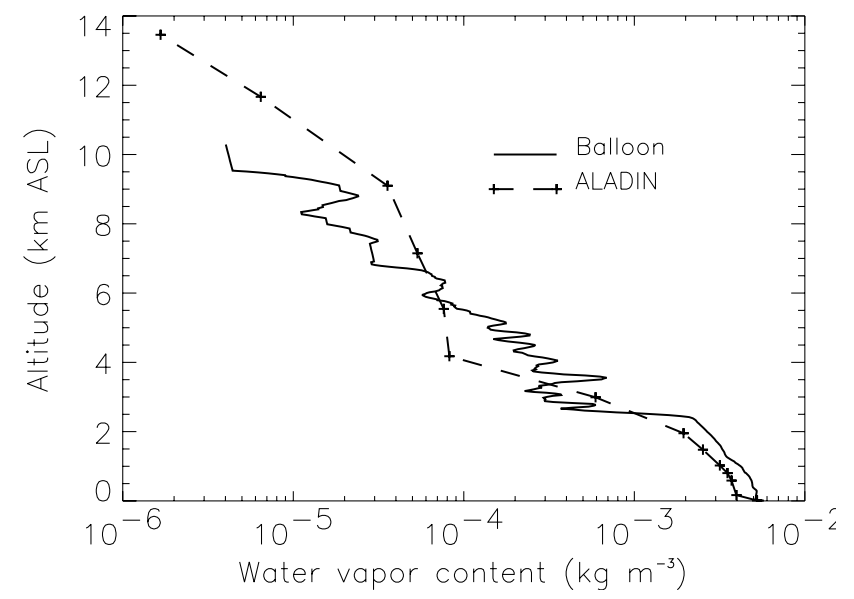

(b)

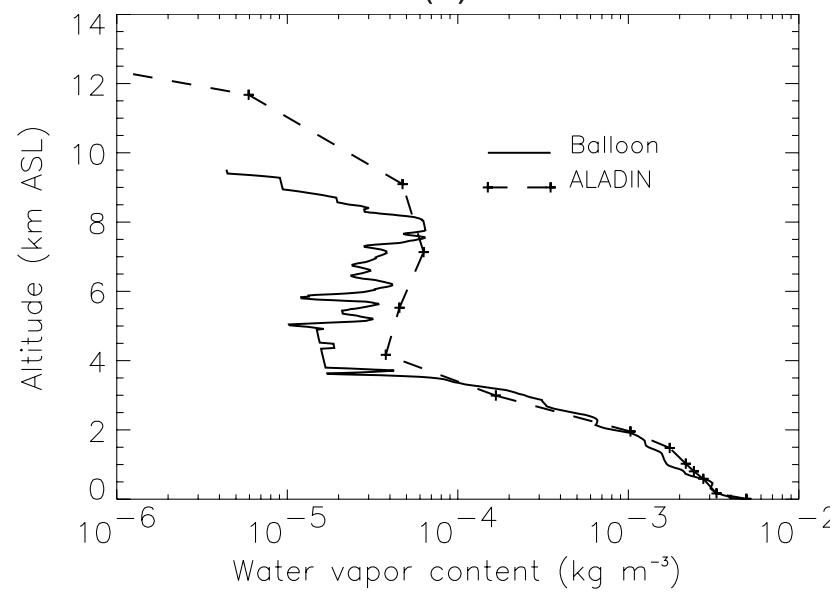

Figure 2. Comparison between WVC profiles extracted from ALADIN and obtained from balloon measurements at 0900 UTC (a) and 1200 UTC (b).

and balloon WVC profiles below $3 \mathrm{~km}$ asl, even though the ALADIN WVC is underestimated by $(1-2) \times 10^{-3} \mathrm{~kg} \mathrm{~m}^{-3}$ (Figure 2a). Above that height the model does not succeed to reproduce the observations: it underestimates the WVC below $6 \mathrm{~km}$ asl and overestimates it above that level. More importantly, these errors do not compensate and the total IWVC estimated with ALADIN is underestimated with respect to the IWVC derived from the sounding (8.4 versus $10.3 \mathrm{~kg} \mathrm{~m}^{-2}$ ). At $1200 \mathrm{UTC}$, an excellent agreement is found below $3.5 \mathrm{~km}$ asl between ALADIN and the sounding (Figure 2b). However, above $3.5 \mathrm{~km}$ asl, the model overestimates the WVC. This leads to an overestimation of the ALADIN-derived IWVC (5.6 versus $4.9 \mathrm{~kg} \mathrm{~m}^{-2}$ ). Keeping in mind that radiosonde data can be dry biased, ALADINderived IWVC at 1200 UTC may not be that much overestimated (accounting for a flat $7 \%$ dry bias between 0 and $15 \mathrm{~km}$ asl, the sounding-derived IWVC would be $5.3 \mathrm{~kg}$ $\mathrm{m}^{-2}$ ). On the other hand, the dry bias cannot explain the differences observed at 0900 UTC between forecast and observations. Based on this, we have estimated the ALADIN IWVC retrieval uncertainty to be on the order of $\pm 20 \%$.

\subsection{The Shipborne Radiometer DRAKKAR}

[16] The two-channel microwave radiometer DRAKKAR, embarked on the Research Vessel Atalante, measured the zenithal incoming radiation at frequencies 23.8 and 36.5 $\mathrm{GHz}$, from which the IWVC and the integrated liquid water content (LWC) were derived [Eymard, 2000]. The retrieval algorithms are simple log linear combinations of the brightness temperatures. The precision of the IWVC (better than 3

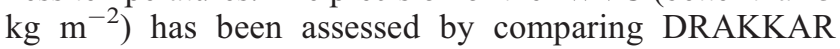
estimates with balloon soundings launched from the ship during the entire FETCH field phase.

\subsection{The Airborne DIAL LEANDRE 2}

[17] The DIAL LEANDRE 2 [Bruneau et al., 2001a, $2001 \mathrm{~b}]$, embarked on the ARAT for water vapor mixing ratio profiling over the Mediterranean, makes use of the laser probing of the atmosphere at two different wavelengths, one being centered on a water vapor absorption line $\left(\lambda_{o n}\right)$, the other, positioned at a closeby value outside of absorption $\left(\lambda_{\text {off }}\right)$, acting as a reference for the scattering and extinction properties of the atmosphere. The water vapor optical depth is determined from the difference of slopes of the backscattered signals (i.e., as the logarithm of ratio of the on-line to the off-line signals). The water vapor mixing ratio is determined by differentiating the water vapor optical depth with respect to range.

[18] The water vapor optical depth was used to estimate an equivalent lidar-derived IWVC in the lower $3 \mathrm{~km}$ of the troposphere. In this case, "equivalent" refers to the fact that LEANDRE 2 really measures $\int q d z$, not $\int(p q) /(R T) d z$. Nevertheless, using the soundings made on 24 March 1998 (at 0900, 1200 and 24000 UTC), it can be shown that $\int(p q) /(R T) d z \simeq \int q d z$ between 0 and $3 \mathrm{~km}$ asl. Given the uncertainty on the LEANDRE 2 water vapor mixing ratio retrievals $\left(\approx 0.35 \mathrm{~g} \mathrm{~kg}^{-1}\right)$, the precision estimated to be on the order of $1 \mathrm{~kg} \mathrm{~m}^{-2}$. In order to carry out meaningful comparisons with other remote sensing instruments (i.e., SSM/I and DRAKKAR) which measured IWVC over a larger depth of the atmosphere, we have added to LEANDRE estimates the IWVC computed with ALADIN (above $700 \mathrm{hPa}, \approx 3 \mathrm{~km}$ asl) along the ARAT flight tracks during F03 using the 1800 UTC forecast. This correction term amounted to approximately $0.7 \mathrm{~kg} \mathrm{~m}^{-2}$. Based on comparison between 0900 and 1200 UTC balloon soundings and coincident ALADIN profiles, we have assumed that the ALADIN estimates of the IWVC above $3 \mathrm{~km}$ could be in error by as much as $40 \%$. We thus have added a $\pm 0.3 \mathrm{~kg} \mathrm{~m}^{-2}$ uncertainty to the precision (uncertainty) on LEANDRE retrievals to account for errors introduced by ALADIN.

\section{4. $\mathrm{SSM} / \mathrm{I}$}

[19] IWVC estimated from SSM/I were computed using measurements made from 3 Defense Meteorological Satellite Program (DMSP) platforms and 4 overpasses: F11 (at 0720 and 1845 UTC), F13 (at 1642 UTC), and F14 (at 1917 UTC). Several algorithms have been published in the literature for the retrieval of the IWVC. The IWVC retrieval algorithms are simple log linear combinations of the brightness temperatures at $19.35,22.235$, and $37.0 \mathrm{GHz}$.

[20] In this study, three algorithms have been used: Petty's integrated water vapor (IWVP) and ocean water vapor (OWV) algorithms [Petty, 1993] and Boukabara's 


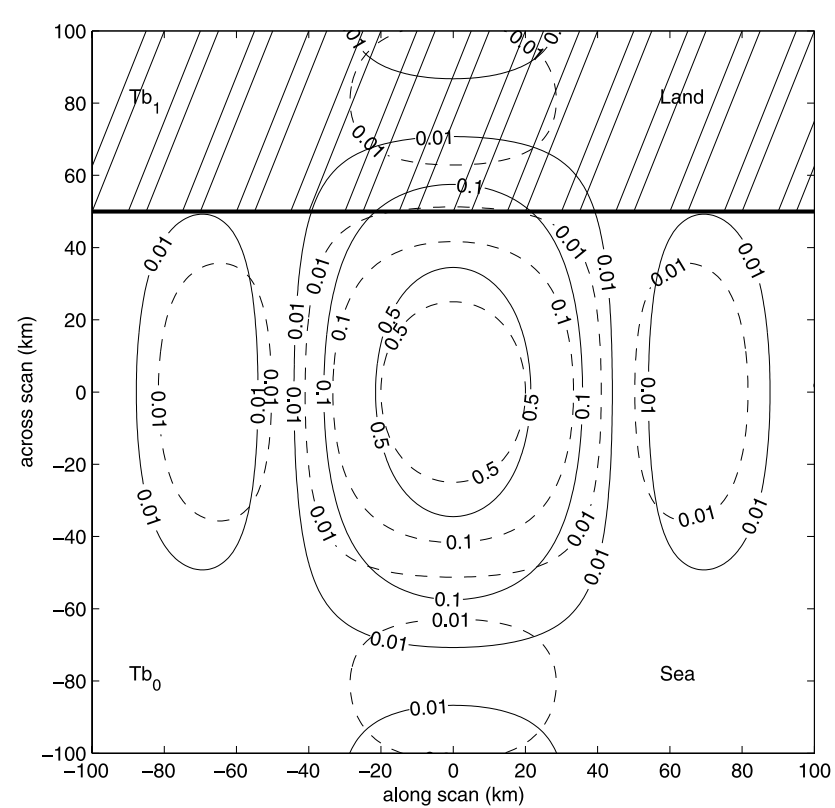

Figure 3. Isolines of the 19 and $22 \mathrm{GHz}$ radiation patterns (solid line and dashed line, respectively) obtained from $\mathrm{SSM} / \mathrm{I}$.

integrated water vapor (IWVB) algorithm [Boukabara, 1997]. The first algorithm was developed by Alishouse et al. [1990] and modified by Petty [1993]. It is presently the standard IWVC product distributed by the Fleet Numerical Meteorology and Oceanographic Center (FNMOC) [SSM/I, 1999]. OWV is defined as

$$
O W V=-3.75+1.507 A-0.01933 A^{2}+0.0002191 A^{3},
$$

where

$$
\begin{aligned}
A= & 232.89393-0.148596 T_{19 V}-1.829125 T_{22 V} \\
& +0.006193 T_{22 V}^{2}-0.36954 T_{37 V} .
\end{aligned}
$$

where $T_{19 \mathrm{~V}}$ is the brightness temperature at $19 \mathrm{GHz}$ in vertical polarization (similar definitions hold for the other subscripted temperatures). The second algorithm proposed by Petty [1993] defines the IWVP as

$$
\begin{aligned}
I W V P= & 174.1+4.368 \log \left(300-T_{19 H}\right)-61.76 \log \left(300-T_{22 V}\right) \\
& +19.58 \log \left(300-T_{37 H}\right) .
\end{aligned}
$$

[21] It is currently used at FNMOC to correct the wind speed estimate for water vapor effects. More recently, Boukabara [1997] proposed a combination of the 5 low resolution channels. The IWVB is defined as

$$
\begin{aligned}
I W V B= & 23.66-1.44 \log \left(280-T_{19 V}\right)-2.47 \log \left(280-T_{19 H}\right) \\
& -2.70 \log \left(280-T_{22 V}\right)-0.81 \log \left(280-T_{37 V}\right) \\
& +2.43 \log \left(280-T_{37 H}\right) .
\end{aligned}
$$

[22] The problem of the mixed land/water measurements ("footprints") inherent to coastal regions such as the GoL can affect the IWVC retrievals significantly [Bennartz, 1999]. The footprint size (at $3 \mathrm{~dB}$ ) for IWVC products is driven by that associated with the $19 \mathrm{GHz}$ frequency $(69 \times$ $43 \mathrm{~km}$ ) [Bennartz, 1999]. In regard to the large footprint of the low frequency channels (19 and $22 \mathrm{GHz}$ ), the SSM/I observations near the coast must be analyzed carefully because of possible land contamination.

[23] Figure 3 presents the isolines of the 19 and $22 \mathrm{GHz}$ radiation patterns. For a sample near the coast, the measured brightness temperature $T b_{m}$ will be a combination of the oceanic and land brightness temperatures $T b_{o}$ and $T b_{l}$. If $f(x, y)$ is the antenna radiation pattern, and if $d$ is the distance between the satellite nadir and the coast, the measured brightness temperature $T b_{m}$ is defined by

$$
\begin{aligned}
T b_{m}= & T b_{l} \int_{d}^{+\infty} \int_{-\infty}^{+\infty} f(x, y) d x d y+T b_{o} \\
& \cdot\left(1-\int_{d}^{+\infty} \int_{-\infty}^{+\infty} f(x, y) d x d y\right)
\end{aligned}
$$

which rewrites as

$$
T b_{m}=T b_{o}+\left(T b_{l}-T b_{o}\right) \int_{d}^{+\infty} \int_{-\infty}^{+\infty} f(x, y) d x d y
$$

[24] Thus, $T b_{m}$ depends on the channel radiation pattern, the distance to the coast, the ocean brightness temperature, and the ocean-land temperature difference.

[25] For each of the SSMI orbit used in the study, the effect of land contamination has been assessed following the study of Goodberlet and Swift [1992]. Near the coast of southern France, the minimum of $T b_{o}$ has been determined as well as the maximum land-sea brightness temperature difference $\left(T b_{l}-T b_{o}\right)$. They are summarized in Table 1 . From this set of brightness temperatures, $T b_{m}$ have been computed at 19,22 , and $37 \mathrm{GHz}$ as a function of the distance to the coast using (7). The $T b_{m}$ data set is then used to compute the integrated water content using the 3 different algorithms used in this study, as well as the error in $\operatorname{IWVC}\left(\triangle I W V C=I W V C\left(T b_{m}\right)-I W V C\left(T b_{o}\right)\right)$ due to land contamination.

[26] Because the radiation patterns are elliptic, and because there is land to the north and to the east of the region of the GoL under scrutiny (materialized by the dashed box in Figure 1), we have computed $T b_{m}$ and $\triangle I W V$ error as

Table 1. Minimum Oceanic Brightness Temperature $\left(T b_{o}\right)$ and Maximum Land-Sea Brightness Temperature Difference $\left(T b_{l}-\right.$ $T b_{o}$ ) for Each DMSP and the Five Frequencies of Interest to This Study

\begin{tabular}{lcccccc}
\hline & DMSP Platform & $19 \mathrm{~V}$ & $19 \mathrm{H}$ & $22 \mathrm{~V}$ & $37 \mathrm{~V}$ & $37 \mathrm{H}$ \\
\hline Minimum $T b_{o}(\mathrm{~K})$ & $\mathrm{F} 1132610$ & 208 & 156 & 220 & 222 & 174 \\
& $\mathrm{~F} 1132610$ & 222 & 180 & 228 & 232 & 143 \\
& $\mathrm{~F} 1315477$ & 221 & 180 & 239 & 230 & 192 \\
& $\mathrm{~F} 1405001$ & 226 & 187 & 233 & 238 & 207 \\
Maximum $T b_{l}-T b_{o}(\mathrm{~K})$ & $\mathrm{F} 1132610$ & 30.5 & 55.5 & 25.0 & 26.0 & 51.5 \\
& $\mathrm{~F} 1132610$ & 30.5 & 56.0 & 28.5 & 28.0 & 56.0 \\
& F13 15477 & 28.5 & 49.0 & 27.0 & 27.5 & 54.5 \\
& F14 05001 & 29.0 & 52.0 & 28.0 & 28.0 & 58.0 \\
\hline
\end{tabular}



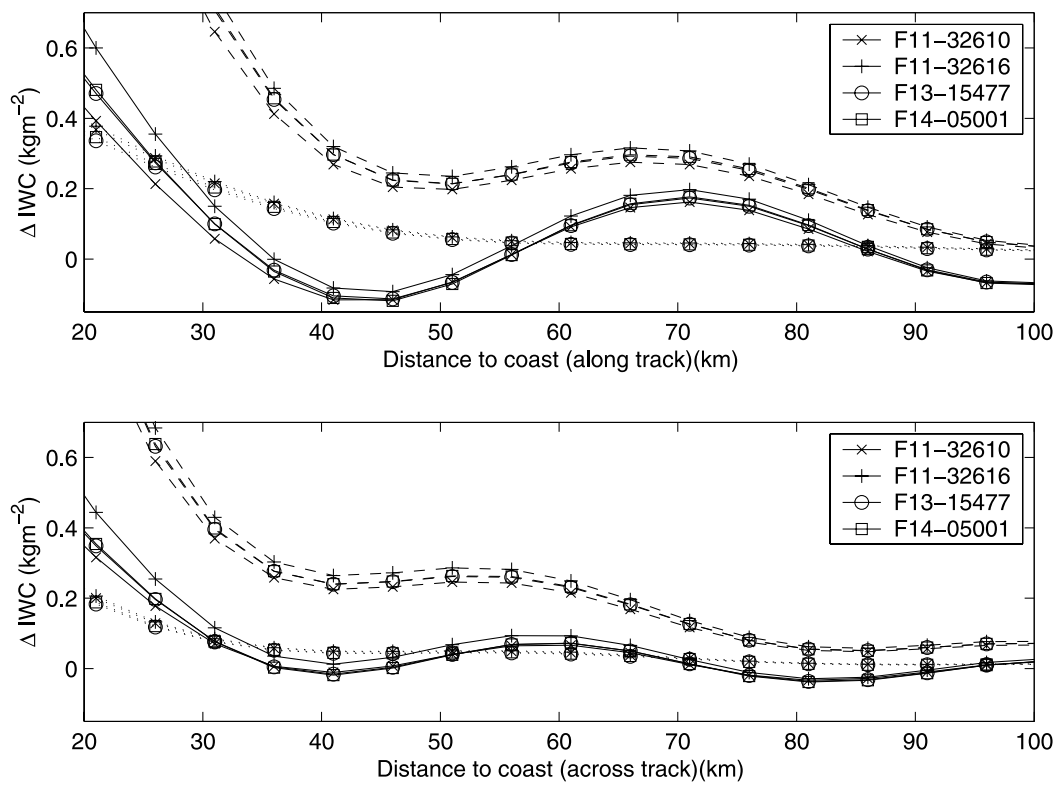

Figure 4. Variation of IWVC error as a function of (a) the distance to the coast along-track cross-scan (upper panel) and (b) the distance to the coast across-track along-scan, as derived from SSM/I. Symbols relate to the four DMSP overpasses. The errors associated with OWV, IWVP, and IWVB are plotted as the solid, dashed, and dotted lines, respectively.

a function of (1) the distance to the coast along-track and across-scan (i.e., a coast to the north) and (2) the distance to the coast across-track and along-scan (i.e., a coast to the east). Figure 4 presents the along-track across-scan (upper panel) and across-track along-scan (lower panel) variation of IWVC errors as a function of the distance to the coast for the three algorithms. It corresponds to the case where the land-sea gradient of brightness temperature was largest (worst case estimate), i.e., F11 32610 (Table 1). At a given distance from the coast, the largest errors are observed to be associated with IWVP. Furthermore, concerning IWVP and IWVB, the errors are always larger in the along-track (cross-scan) direction. OWV behaves somewhat similarly, except for a region between 30 and $50 \mathrm{~km}$ where the error of IWVC is smaller in the alongtrack (cross-scan) direction.

[27] On 24 March 1998, most of the measurements relevant to this study were made at distances from the coast between 50 and $100 \mathrm{~km}$. When considering the least favorable case (along-track cross-scan direction), for distances greater than $50 \mathrm{~km}$ the error is always smaller than $0.4 \mathrm{~kg} \mathrm{~m}^{-2}$ regardless of the algorithm selected (IWVP being the worst case). For the OWV and IWVB algorithms, the error is even less than $0.2 \mathrm{~kg} \mathrm{~m}^{-2}$. These errors are much smaller than the precision of the retrieval algorithms which is on the order of $2-3 \mathrm{~kg} \mathrm{~m}^{-2}$ [Katsaros and Brown, 1991]. The root-square-mean (RMS) deviation (assessed by comparing SSM/I estimates with balloon soundings) has been assessed to be on the order of $2.5 \mathrm{~kg} \mathrm{~m}^{-2}$ in coastal regions [Bennartz, 1999] and $1.6 \mathrm{~kg} \mathrm{~m}^{-2}$ over homogeneous water surfaces [Schlüssel and Emery, 1990]. Finally, the sensitivity limit of the algorithms is considered to be of the order of $5 \mathrm{~kg} \mathrm{~m}^{-2}$. As show in the following, low IWVCs (less than $10 \mathrm{~kg} \mathrm{~m}^{-2}$ ) are commonly associated with Mistral/Tramontane events over the GoL.
[28] In the following, we have discarded coastal pixels within $50 \mathrm{~km}$ of the coastline. Over the ocean, the sampling of the data presented in this paper is $0.1^{\circ} \times 0.1^{\circ}$.

[29] The LWC retrievals (not shown) have also been investigated. LWC larger than $10 \mathrm{~kg} \mathrm{~m}^{-2}$ were associated with the Tyrrhenian Sea cyclone and were also observed to the north of the Atlas Mountains (Morocco). In the remaining of the Mediterranean basin (and in the GoL), LWC was negligible despite a significant cloudiness.

[30] Figure 5 exhibits the histograms of IWVC distribution in a domain comprised between $3^{\circ} \mathrm{E}$ and $8^{\circ} \mathrm{E}$ and $40^{\circ}-$ $44^{\circ} \mathrm{N}$ (see box superimposed on Figure 6e) for the $4 \mathrm{SSM} / \mathrm{I}$ passages and the three algorithms considered in this study. The OWV product is defined as a linear combination of brightness temperatures, while the IWVP and IWVB products are defined as a linear combination of the logarithm of brightness temperatures. As a result, the OWV product generally exhibits a greater sensitivity than the products of the other two algorithms. Figure 5 illustrates the fact that the sensitivity limit of the OWV product is lower than for the other two products. In the morning (0720 UTC), when the conditions over the GoL are most humid, the OWV and IWVB distributions exhibit similar behaviors while the IWVP distribution is shifted toward larger IWVC values by $1.5 \mathrm{~kg} \mathrm{~m}^{-2}$, showing less sensitivity. Later, in drier conditions, the OWV algorithm was able to detect IWVC values as low as $5.5 \mathrm{~kg} \mathrm{~m}^{-2}$ while the other two algorithms could not detect IWVC values below $8 \mathrm{~kg} \mathrm{~m}^{-2}$. Finally the IWVP (OWV) algorithm always gave the largest (smallest) average IWVC values over the selected domain (Table 2). The largest standard deviation was associated with the OWV algorithm, indicating that it was noisier than the other two algorithms. The less noisy algorithm was IWVB. In the following, comparisons with retrievals from other instruments were carried out using the OWV product only. The 
(a)

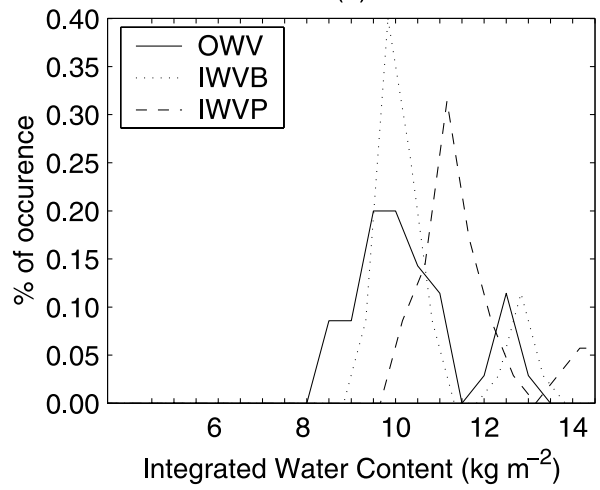

(c)

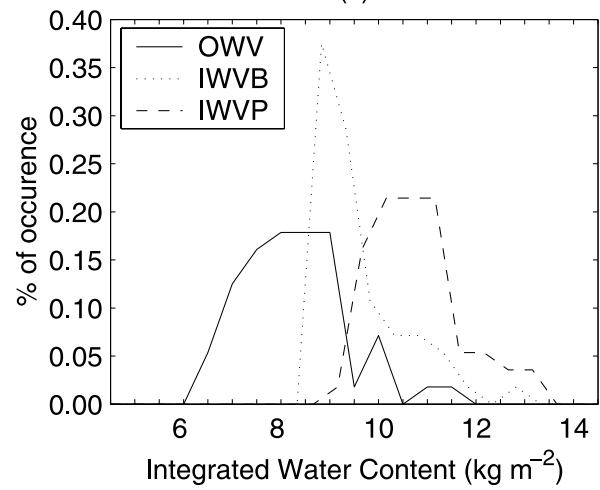

(b)

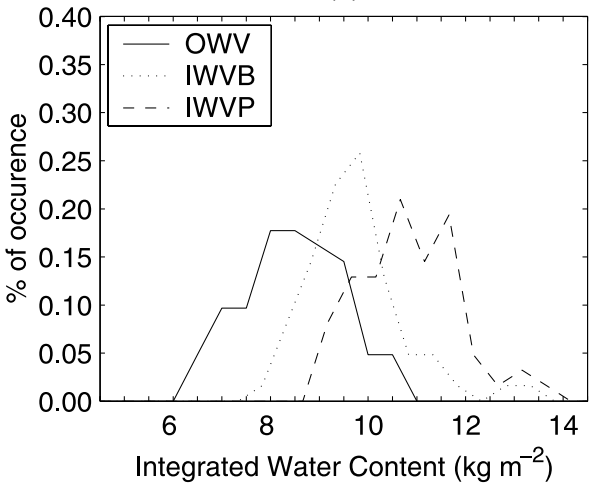

(d)

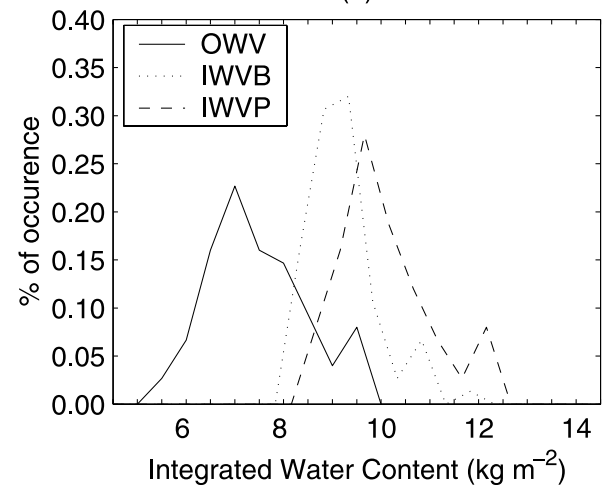

Figure 5. Histograms of IWVC distribution in a domain comprised between $3^{\circ} \mathrm{E}$ and $8^{\circ} \mathrm{E}$ and $40^{\circ}-$ $44^{\circ} \mathrm{N}$ for the four SSM/I passages and the three algorithms (OWV, IWVP, and IWVB) considered in this study: (a) F11 at 0720 UTC, (b) F13 at 1642 UTC, (c) F11 at 1845 UTC, and (d) F14 at 1917 UTC.

OWV algorithm was selected because of its greater sensitivity to lower IWVC values, but also because OWV retrievals exhibited the smallest bias of all algorithms with the data used for the comparison (not shown). Note that in section 5 only comparisons with OWV retrievals are discussed. Finally, it is the most widely used algorithm when it comes to processing SSM/I data.

\section{IWVC Distribution Over the Northern Mediterranean on 24 March 1998}

[31] In this section, we analyze the spatiotemporal evolution of the IWVC over the northern Mediterranean using OWV retrievals (Figure 7) and ALADIN forecasts (Figure 6). As shown in this section, the ALADIN forecasts are an excellent complement to SSM/I observations: they do fill some gaps in the observations but also are powerful tools for discriminating the different IWVC contributions as a function of height. The SSM/I OWV product was also compared to ALADIN retrievals.

\section{1. $\mathrm{SSM} / \mathrm{I}$}

[32] The evolution of the IWVC over the northern Mediterranean estimated from SSM/I OWV product at 0720, 1642, 1845, and 1917 UTC is shown in Figure 7. In the morning (at 0720 UTC) (Figure 7a), a region characterized by IWVC values less than $12 \mathrm{~kg} \mathrm{~m}^{-2}$ was observed to extend from the GoL to the Gulf of Genoa (GoG). These low values were related to the cold-air outbreaks from the
Rhone and Aude valleys (over the GoL) and from the Po valley (over the GoG). IWVC values larger than $14 \mathrm{~kg} \mathrm{~m}^{-2}$ were observed over the Tyrrhenian Sea (where the Alpine lee cyclone was located) as well as south of the Balearic Islands, close to the coast of Morocco and in the vicinity of the Atlas mountain range, where a cyclone was positioned. At 1642 UTC, the average IWVC over the GoL decreased to $10 \mathrm{~kg} \mathrm{~m}^{-2}$ while still being of the order of $12 \mathrm{~kg} \mathrm{~m}^{-2}$ over the Ligurian Sea. At 1845 UTC, IWVC as low as $8 \mathrm{~kg}$ $\mathrm{m}^{-2}$ were observed over the GoL $\left(10 \mathrm{~kg} \mathrm{~m}^{-2}\right.$ over the GoG). Furthermore, the influence of the Morocco cyclone was limited to the southwest corner of the domain. This was due to the intensification of the Ligurian Sea outflow [Flamant, 2002] and the related dry flow which pushed further east the moister air masses circulating around the cyclone offshore of the Atlas range. At 1917 UTC, the GoL exhibited the lowest IWVC observed on that day $(8 \mathrm{~kg}$ $\mathrm{m}^{-2}$ ). Such low values were also observed over the GoG.

\subsection{ALADIN}

[33] The evolution of the IWVC over the northern Mediterranean derived from ALADIN forecasts at 0600, 0900, $1200,1500,1800$, and 2100 UTC is shown in Figure 6. The general features observed on the SSM/I data are reproduced by ALADIN: (1) the low IWVC over the GoL and GoG and the higher values associated with the Alpine and Atlas lee cyclones (which in turn ascertain the SSM/I observations in these regions) and (2) the spatiotemporal evolution of these regions. Over the GoL, the driest periods were forecasted at 
(a)

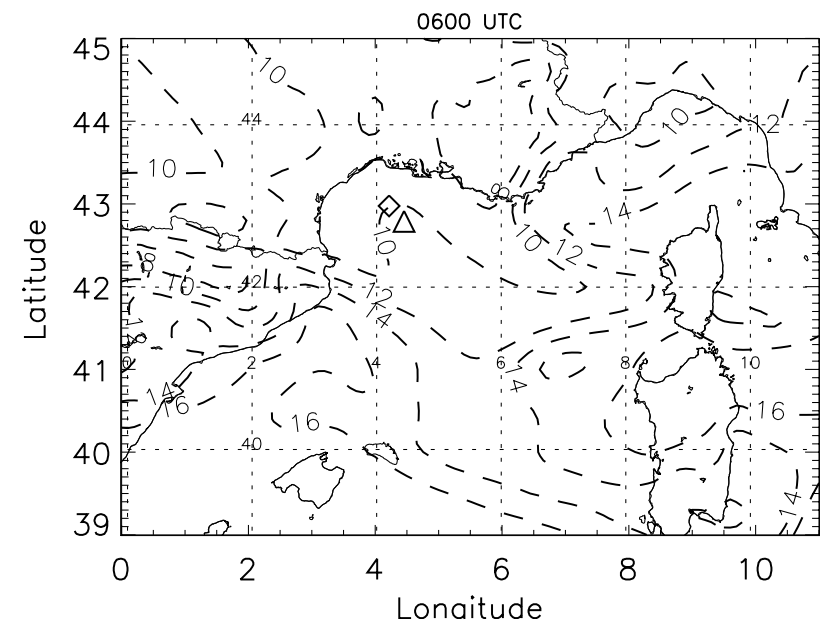

(c)

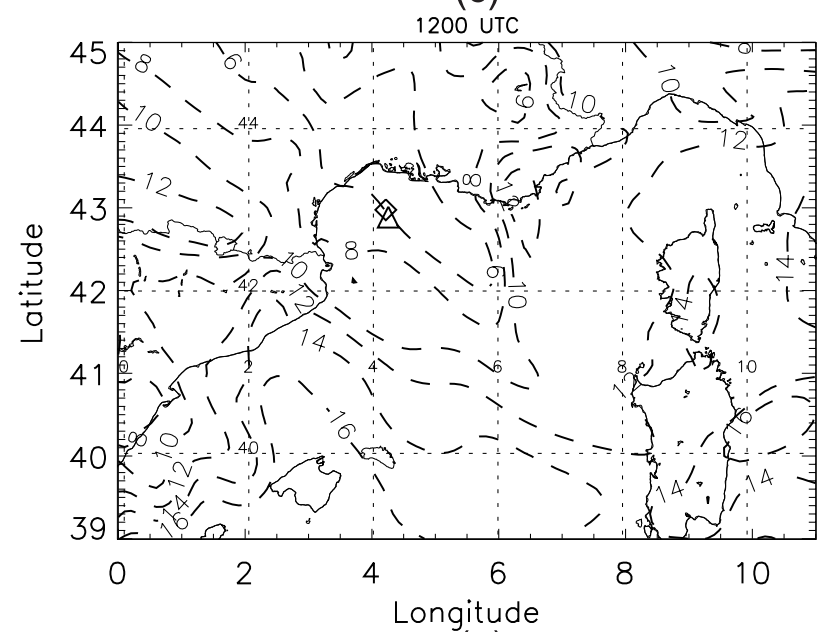

(e)

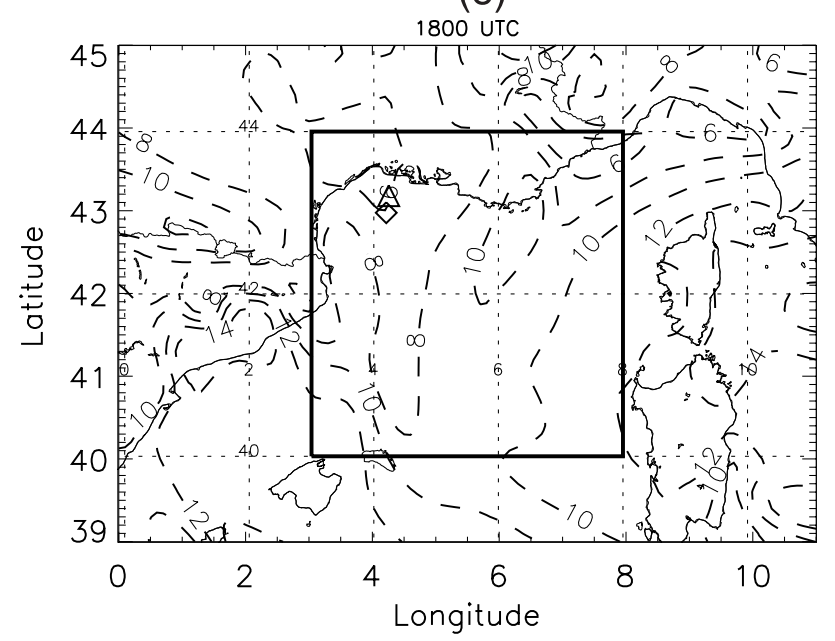

(b)

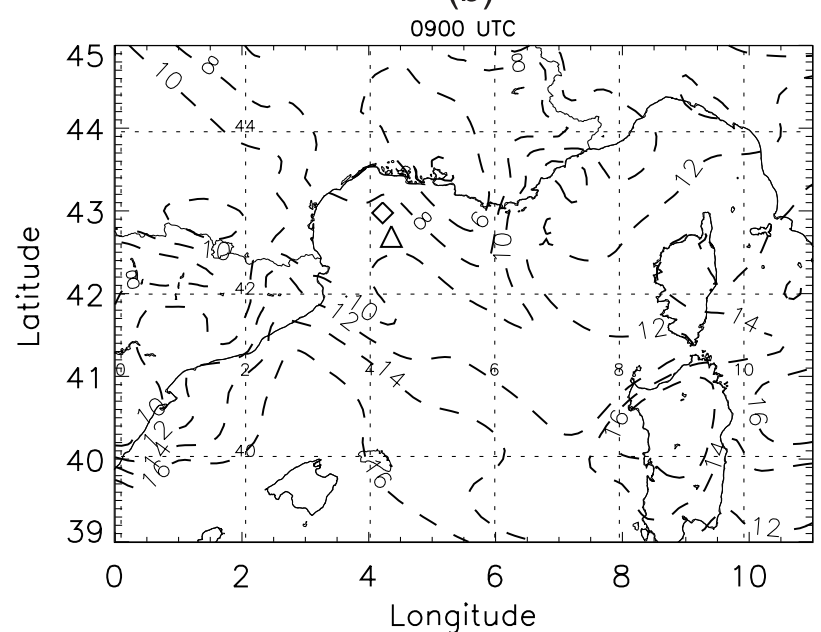

(d)

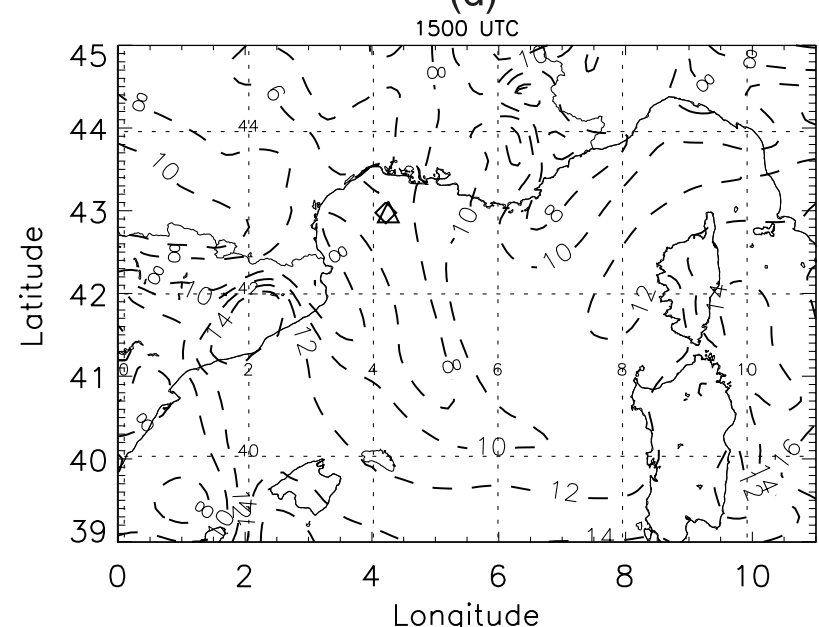

$(f)$

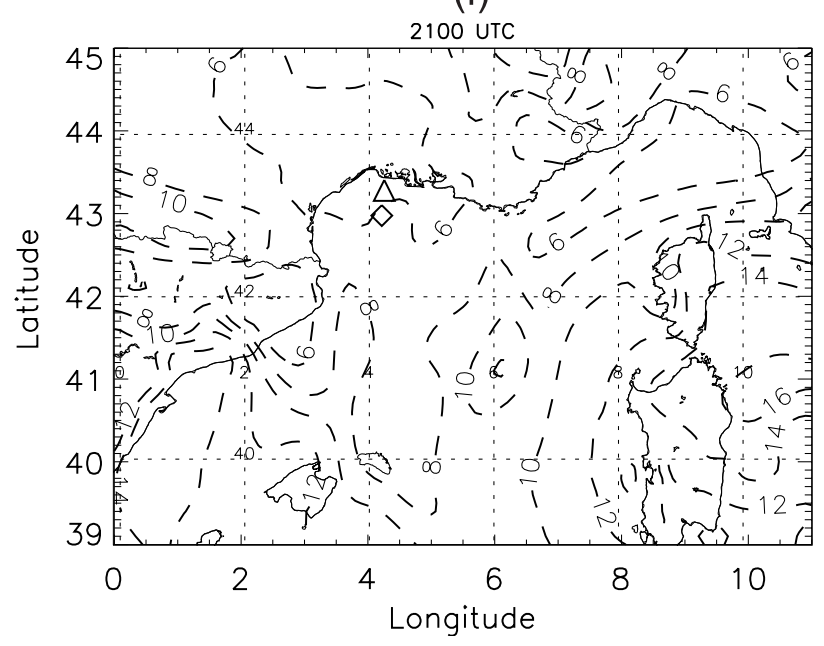

Figure 6. IWVC forecasted by the operational model ALADIN at (a) 0600, (b) 0900, (c) 1200, (d) 1500, (e) 1800 , and (f) 2100 UTC on 24 March 1998. Superimposed are iso-IWVC between 2 and $16 \mathrm{~kg} \mathrm{~m}^{-2}$ with $2 \mathrm{~kg} \mathrm{~m}^{-2}$ increments. The diamond and the triangle indicate the position of the ASIS buoy and the Research Vessel Atalante, respectively. The box superimposed on (e) delimits the area in which IWVC extracted from the ALADAIN forecasts and retrieved with SSM/I are being compared (see Figure 5). 
Table 2. IWVC (Mean and Standard Deviation) Estimated From Four DMSP Platforms on 24 March 1998 Over the GoL (Between $3^{\circ} \mathrm{E}$ and $8^{\circ} \mathrm{E}$ and $40^{\circ}-44^{\circ} \mathrm{N}$ ) for the Four SSM/I Passages and the Three Algorithms Considered in This Study: Petty's IWVP and OWV Algorithms [Petty, 1993] and Boukabara's IWVB Algorithm [Boukabara, 1997]

\begin{tabular}{ccccccc}
\hline DMSP Platform & IWVP & $\sigma_{I W V P}$ & OWV & $\sigma_{O W V}$ & IWVB & $\sigma_{I W V B}$ \\
\hline F11 at 0720 UTC & 11.6 & 1.35 & 10.8 & 1.23 & 10.6 & 1.12 \\
F13 at 1642 UTC & 10.1 & 1.02 & 8.95 & 1.03 & 9.9 & 1.02 \\
F11 at 1845 UTC & 10.6 & 0.94 & 8.79 & 1.08 & 9.8 & 0.89 \\
F14 at 1917 UTC & 9.9 & 0.92 & 7.96 & 1.01 & 9.4 & 0.68 \\
\hline
\end{tabular}

${ }^{\mathrm{a}}$ Mean values and standard deviations are in $\mathrm{kg} \mathrm{m}^{-2}$.

1200 and 2100 UTC, during established Mistral periods. Conversely, the moistest periods were forecasted at 0600 and 0900 UTC, in connection with a northwesterly synoptic flow. The best correspondence between SSM/I and ALADIN IWVC fields was found to be as follows: 0720 with 0900 UTC, 1642 and 1845 with 1800 UTC, and 1917 with 2100 UTC.

[34] The temporal evolution of IWVCs in the region of the FETCH operations has been analyzed by investigating the diurnal evolution of the WVC (i.e., $\rho$ in (1)) over the
GoL at the position of the Research Vessel Atalante (Figure 8a). Figure $8 \mathrm{a}$ shows that, between 850 and 300 $\mathrm{hPa}(\approx 1.5$ and $9 \mathrm{~km}$ asl), the WVC fluctuated by an order of magnitude between 0600 and 1800 UTC, the smallest (largest) values being forecasted at 1200 UTC (0900 UTC). Above $300 \mathrm{hPa}$, the $\mathrm{WVC}$ profiles looked very much alike. Below $850 \mathrm{hPa}$, the WVC was largest at 0600 and 0900 UTC. A great variability in terms of wind direction was also observed below $300 \mathrm{hPa}$ (Figure 8b). In the MABL (below $925 \mathrm{hPa} \approx 1 \mathrm{~km}$ asl), the wind was seen to turn progressively from $340^{\circ}$ at $0900 \mathrm{UTC}$ to $10^{\circ}$ at 1800 UTC and the wind speed (Figure 8c) increased from 10 to $18 \mathrm{~m} \mathrm{~s}^{-1}$. The greatest wind speed and direction variability was observed between 925 and 200 $\mathrm{hPa}(\approx 1$ and $11.5 \mathrm{~km}$ asl), the largest wind shear occurring immediately above the MABL, between 925 and $700 \mathrm{hPa}$ $(\approx 1$ and $3 \mathrm{~km}$ asl). At $700 \mathrm{hPa}$, the wind direction varied from $310^{\circ}$ at $0600 \mathrm{UTC}$ to $35^{\circ}$ at $1800 \mathrm{UTC}$. The flow below $600 \mathrm{hPa}(\approx 4 \mathrm{~km}$ asl) was observed to decelerate while accelerating above. In the latter case, the acceleration was due to the strengthening of the upper level jet (at $400 \mathrm{hPa} \approx 7 \mathrm{~km}$ asl) as forecasted by ALADIN (Figure 9). However, this progressive acceleration was not "transmitted" downward to the lowest levels of the troposphere, (a)

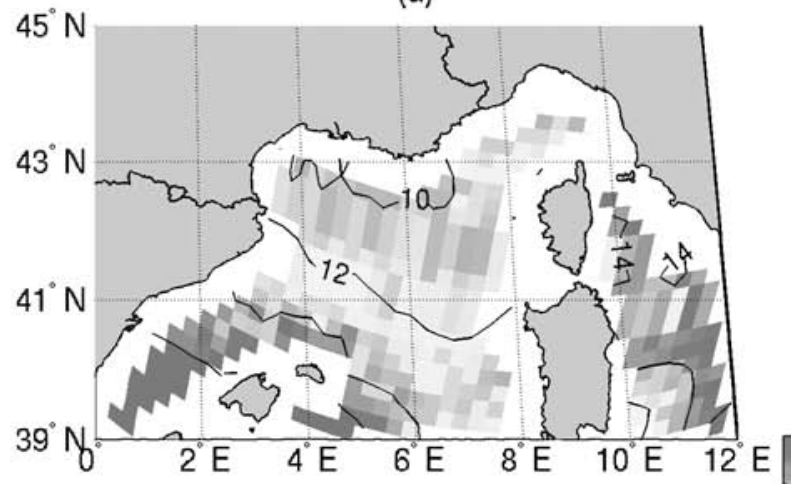

(c)

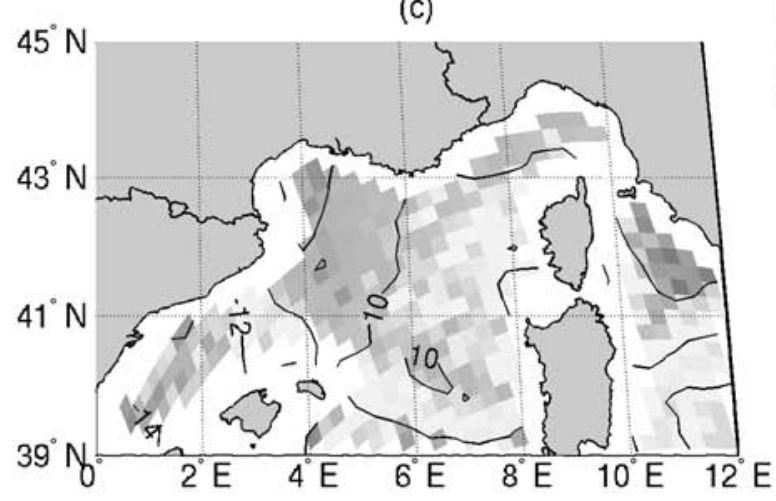

(b)

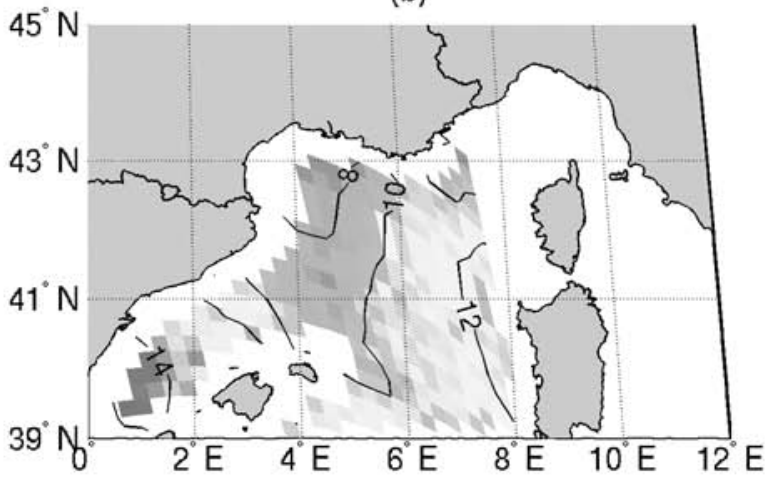

(d)

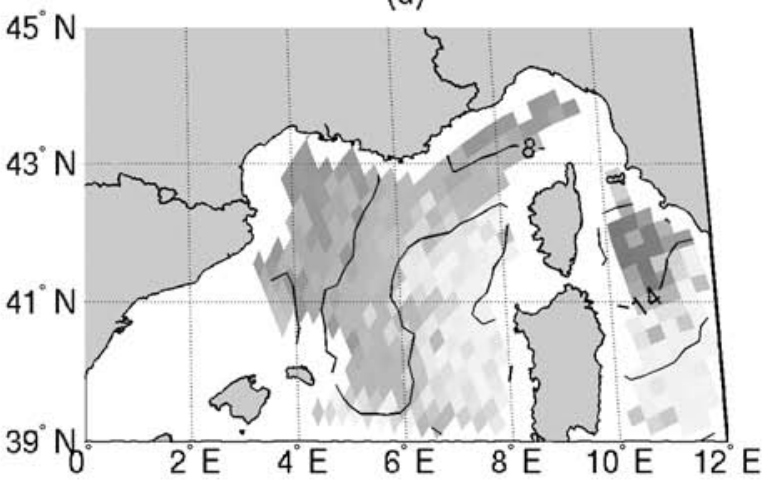

Figure 7. IWVC estimated from DMSP/SSM/I platforms using Petty's OWV algorithm: F11 at 0720 UTC (a), F13 at 1642 UTC (b), F11 at 1845 UTC (c), and F14 at 1917 UTC (d). Superimposed are isoIWVC between 2 and $16 \mathrm{~kg} \mathrm{~m}^{-2}$ with $2 \mathrm{~kg} \mathrm{~m}^{-2}$ increments. See color version of this figure at back of this issue. 
(a)

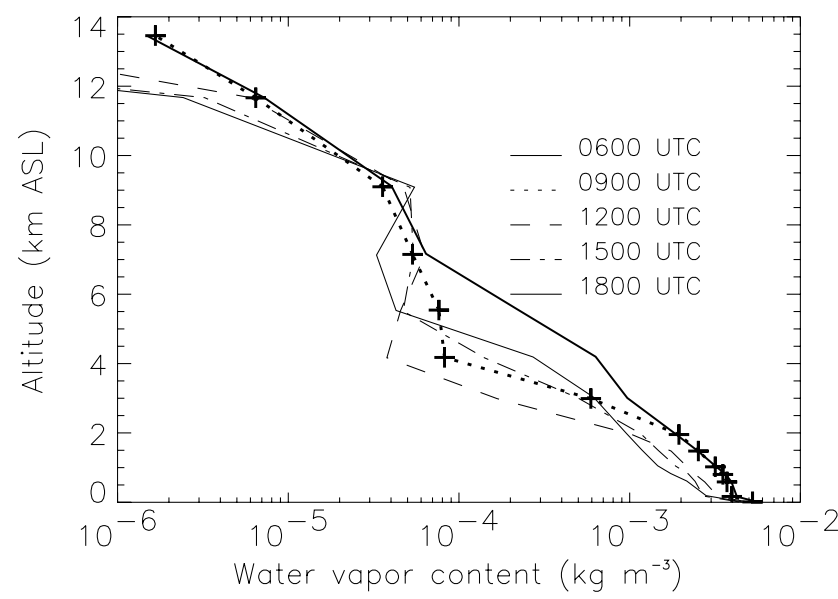

(b)

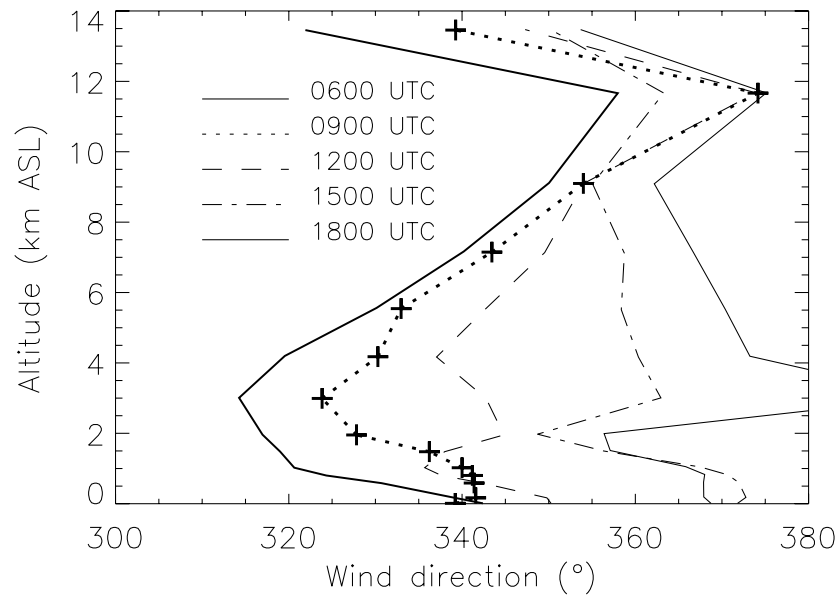

(c)

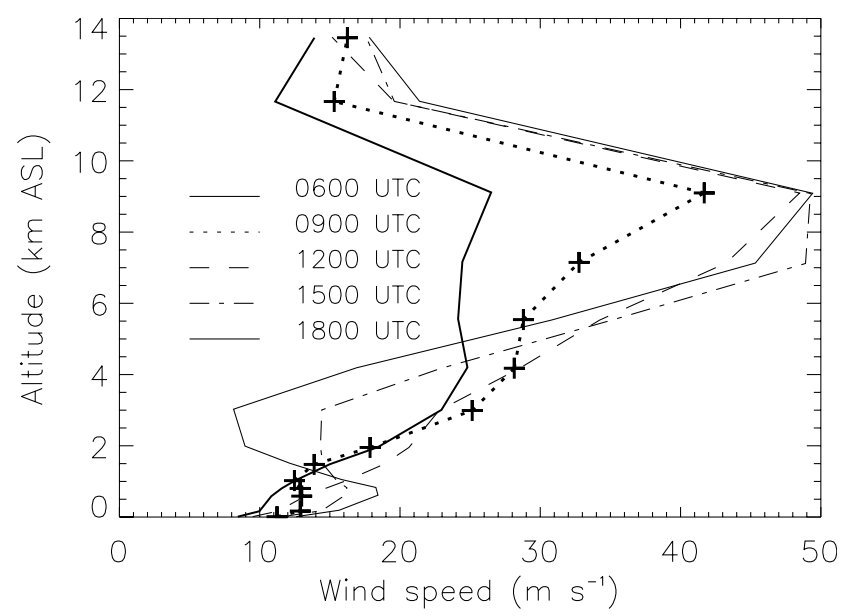

Figure 8. WVC (a), wind direction (b), and wind speed (c) profiles over the GoL extracted from ALADIN forecasts between 0600 and 1800 UTC at the location of the Research Vessel Atalante.

due to an increasingly prevailing contribution of a northeasterly flow in connection with the strengthening outflow from the GoG and the deepening cyclone over the Tyrrhenian Sea [Flamant, 2002]. This is illustrated by the ALADIN wind field at $700 \mathrm{hPa}$ shown in Figure 10 where the flow from the GoG was observed to strengthen during the day, disturbing the established Mistral flow between 1500 and 1800 UTC. In addition, the strengthening northeasterly winds generated a sheltered region (i.e., a region of reduced wind speed in the wake of an obstacle) in the lee of the Alps which progressively extended over the GoL, explaining the large directional and speed shears observed at 1800 UTC in Figures $8 \mathrm{~b}$ and $8 \mathrm{c}$.

[35] Given the evolution of the wind direction with time, the WVC increase observed in Figure $8 \mathrm{a}$ above $850 \mathrm{hPa}$ between 1200 and 1800 UTC, could be due to (1) advection of moisture from the cyclone or/and (2) diabatic effects occurring in the lee of the Alps. This has been partially investigated, using ALADIN, by analyzing separately the IWVC contributions below and above $850 \mathrm{hPa}$ (Figures 11 and 12, respectively). Below $850 \mathrm{hPa}$ (Figure 11), small IWVC values were forecasted to be associated with the cold-air outbreaks over the GoL and the GoG throughout the day. A similar behavior was evidenced over the GoL above $850 \mathrm{hPa}$ (Figure 12). However, in the case of the GoG, the behavior was somewhat different: small IWVC were observed to the north of the GoG while larger values were associated with the southern part of the Ligurian Sea (north of Corsica), most likely in connection with the presence of the cyclone. This effect is most marked at 1500 UTC, where a "tongue" of IWVCs larger than $5 \mathrm{~kg} \mathrm{~m}^{-2}$ was observed to push southwestward the IWVC banner associated with the Mistral/ Tramontane flow. At 1800 UTC, the Mistral/Tramontane banner was pushed further to the southwest. It was no longer observed at $2100 \mathrm{UTC}$, except close to the offshore of Arles (see Figure 1). From Figure 12, it appears that, above 850 $\mathrm{hPa}$, the evolution of the IWVC over the GoL was not influenced directly by moisture advection from the cyclone. This was confirmed by the back-trajectories computed with the Hybrid Single-Particle Lagrangian Integrated Trajectory (HYSPLIT4) Model (courtesy of NOAA Air Resource Laboratory (http://www.arl.noaa.gov/ready/hysplit4.html)) ending at $3 \mathrm{~km}$ asl over the GoL every 3 hours between 0600 and 2100 UTC (Figure 13). This figure evidences that 
(a)

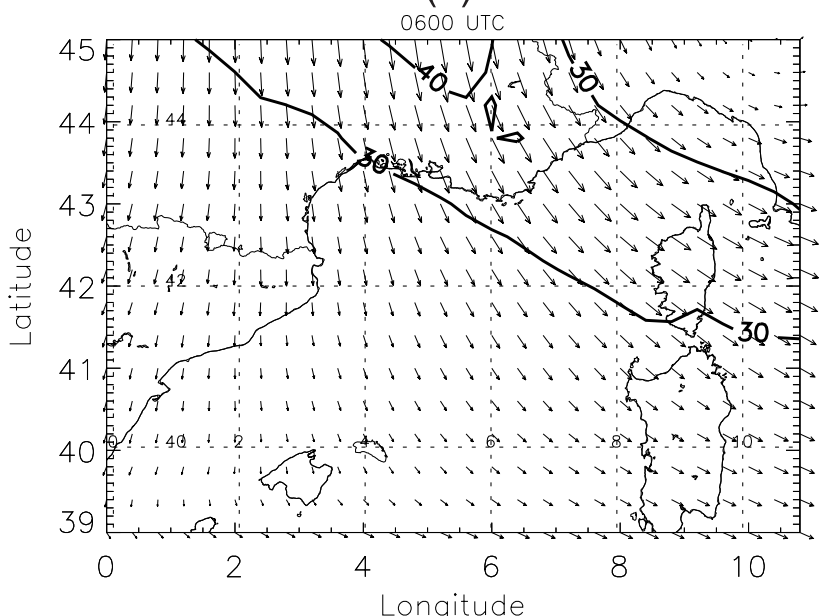

(c)

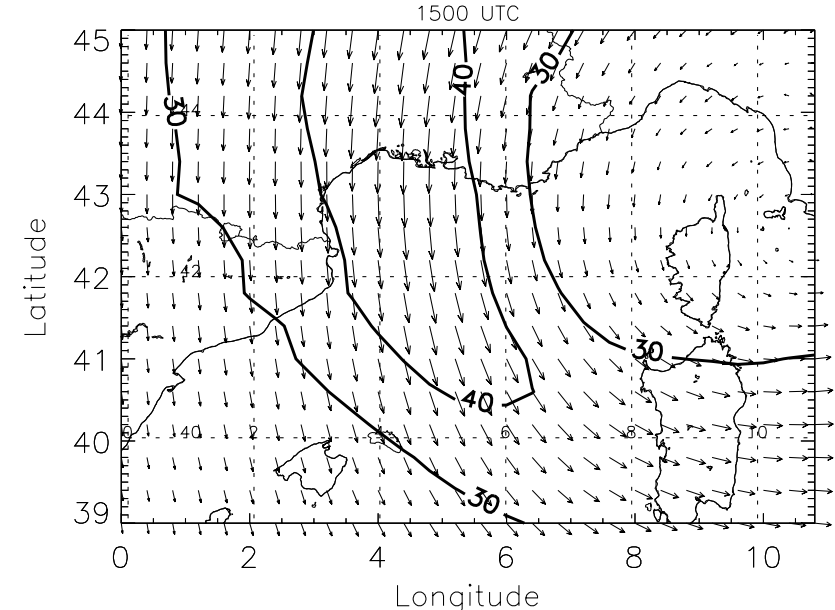

(e)

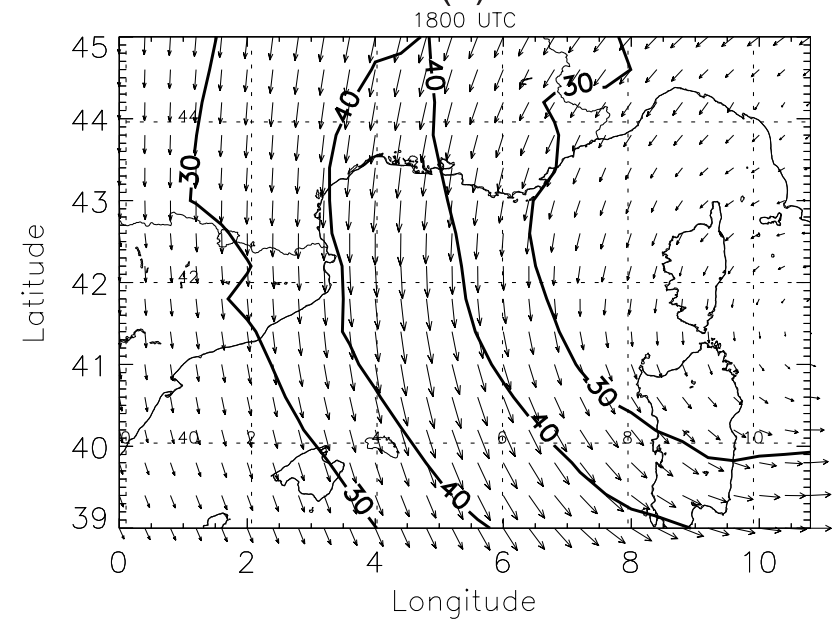

(b)

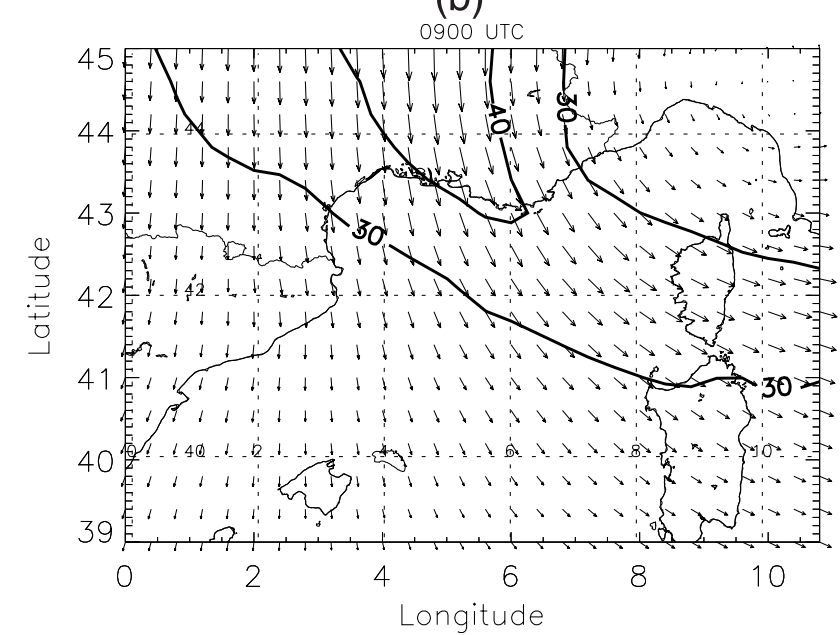

(d)

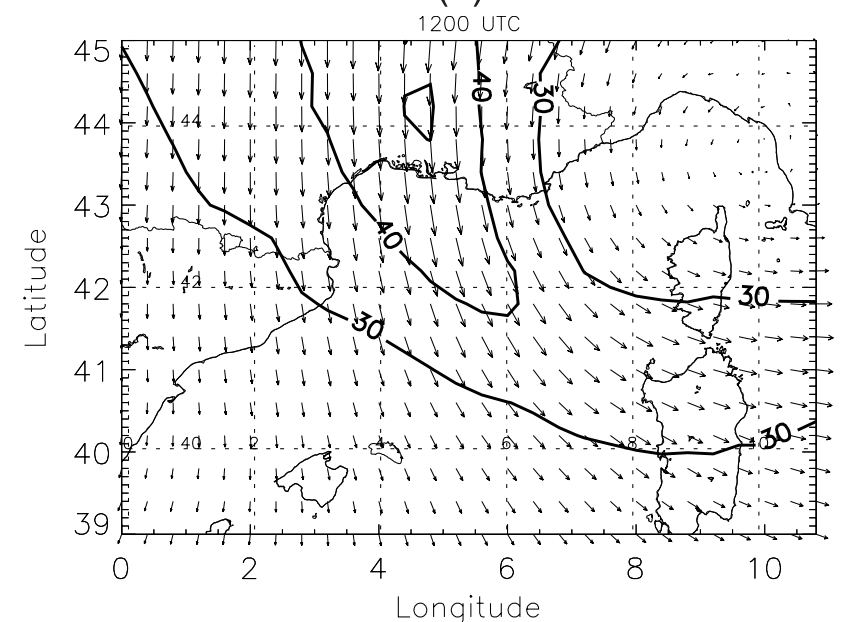

(f)

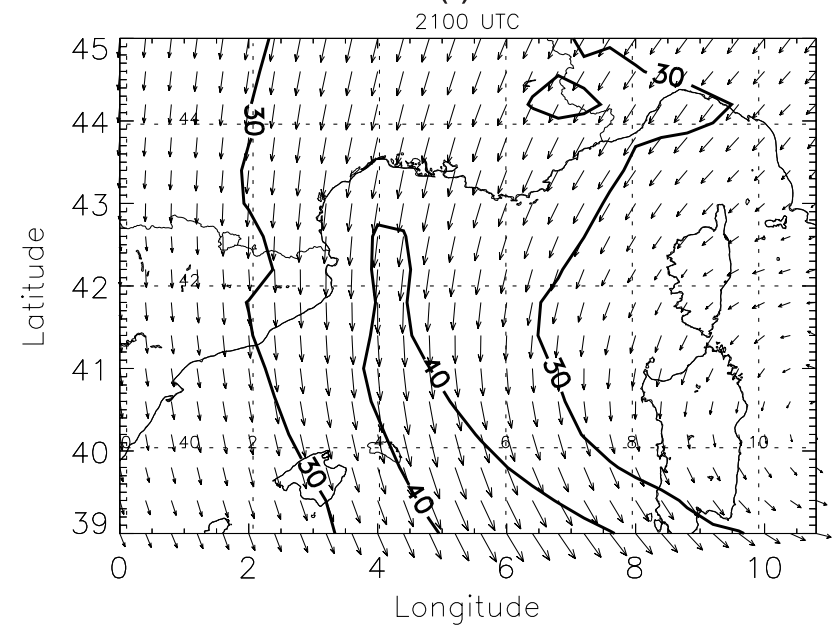

Figure 9. Wind fields forecasted at $400 \mathrm{hPa}$ on 24 March 1998 by ALADIN at (a) 0600, (b) 0900, (c) 1200 , (d) 1500 , (e) 1800 , and (f) 2100 UTC. Superimposed are isotachs between 30 and $50 \mathrm{~m} \mathrm{~s}^{-1}$ with $10 \mathrm{~m} \mathrm{~s}^{-1}$ increments.

for the previous 24 hours, the air masses arriving in the vicinity of the location of the Research Vessel Atalante had traveled over continental France. Nevertheless, the evolution of back-trajectories with time also evidenced the increasing influence of the deepening cyclone on the air mass circulation over the GoL. The influence of the cyclone on the IWVC could then be the result of air mass transformation processes in the lee of the Alps. According to 
(a)

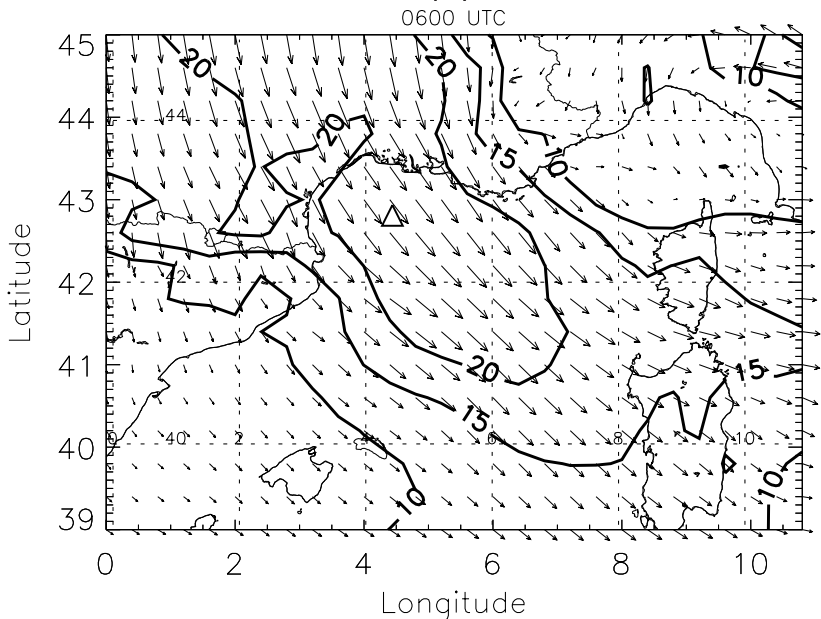

(c)

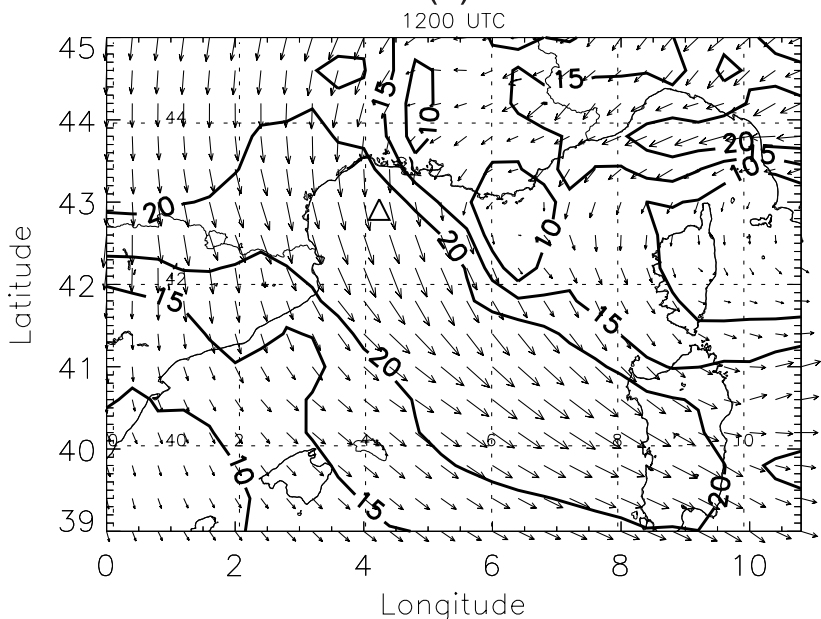

(e)

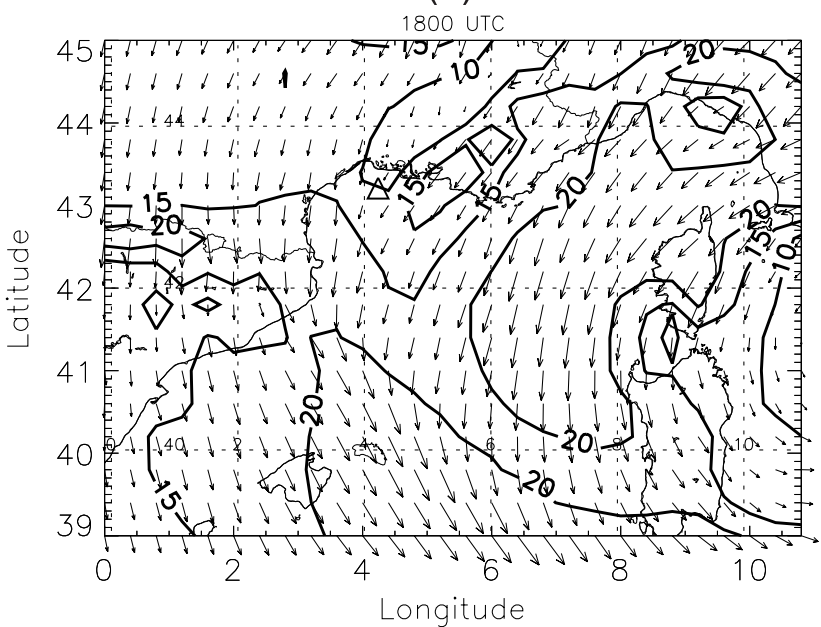

(b)

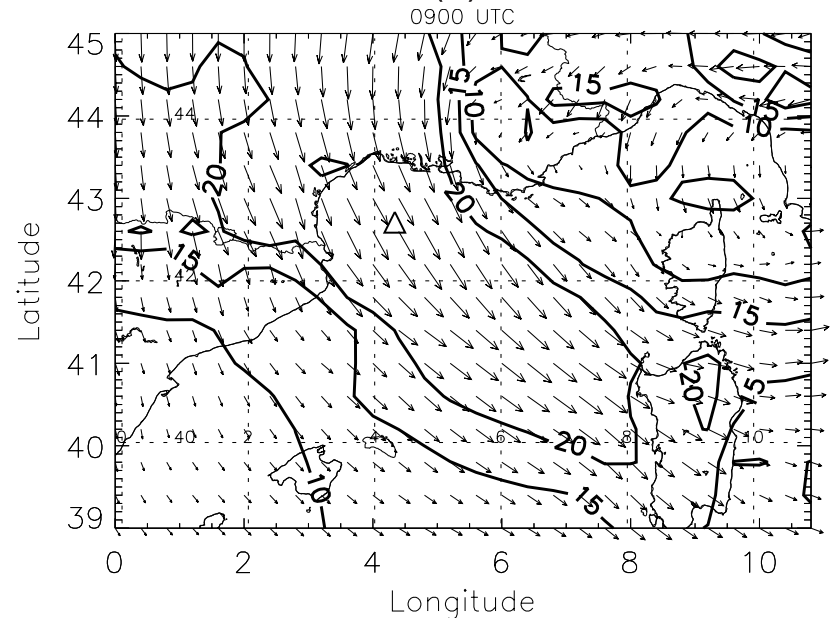

(d)

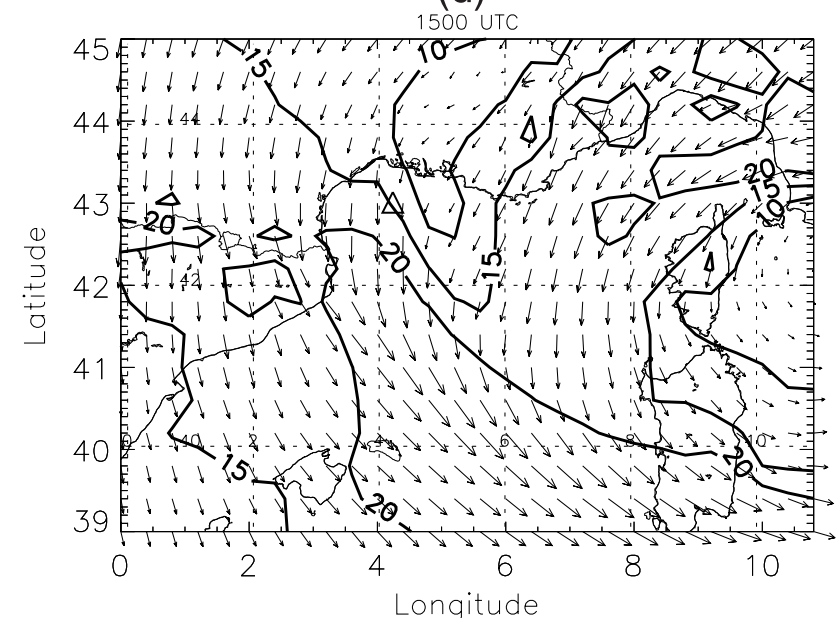

(f)

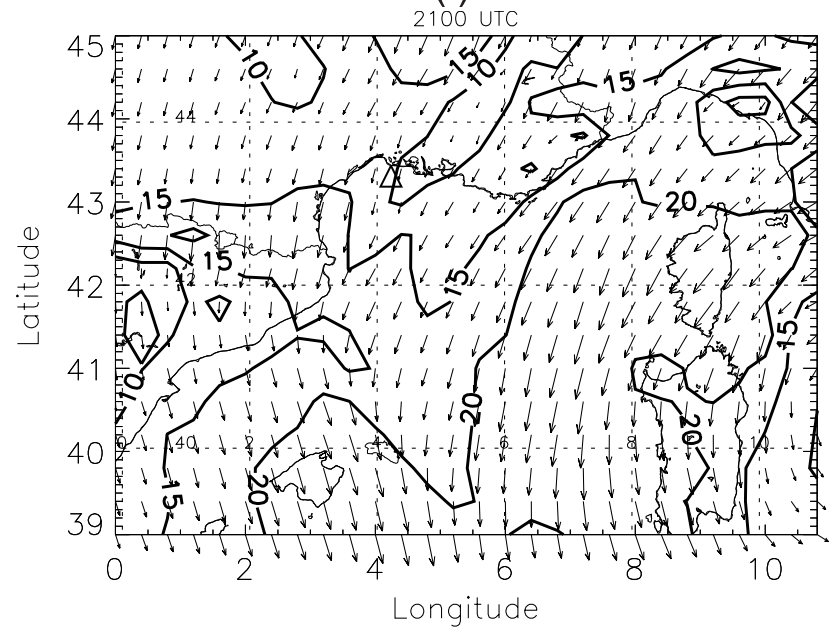

Figure 10. Same as Figure 9, but for the wind field at $700 \mathrm{hPa}$. Isotachs are between 10 and $20 \mathrm{~m} \mathrm{~s}^{-1}$ with $5 \mathrm{~m} \mathrm{~s}^{-1}$ increments.

Figure 13, this influence should be most marked between 1500 and 2100 UTC.

\subsection{Comparison of SSM/I-Derived and ALADIN-Derived IWVCs}

[36] In Figure 14, we compare the histogram distribution of SSM/I OWV extracted on the domain shown in
Figure 6e at 1642 and 1845 UTC with the ALADINderived IWVC at 1800 UTC. The three distributions were in good agreement with one another. This is consistent with the fact that both SSM/I passages sampled the moisture field over the GoL during perturbed Mistral conditions. The value and the position of the maximum of occurrence for the ALADIN-derived and SSM/I- 
(a)

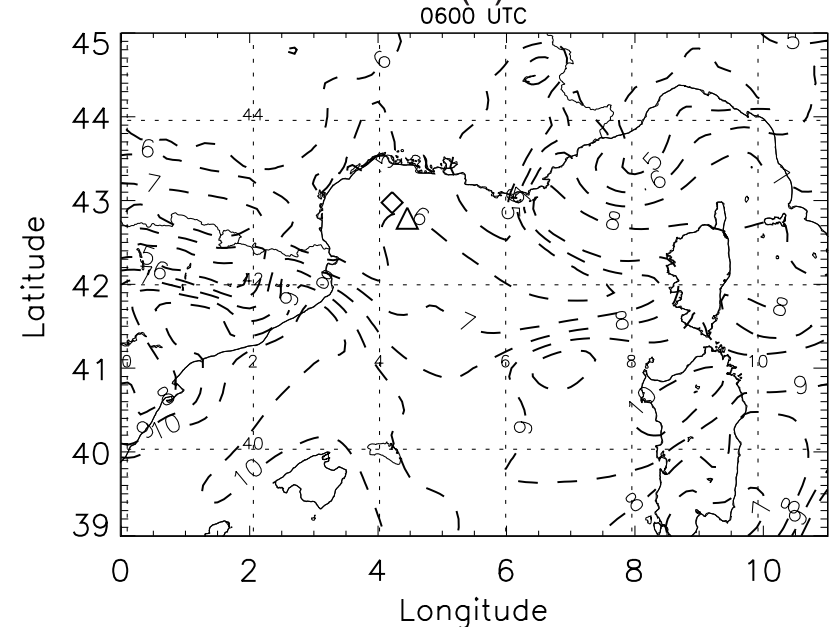

(c)

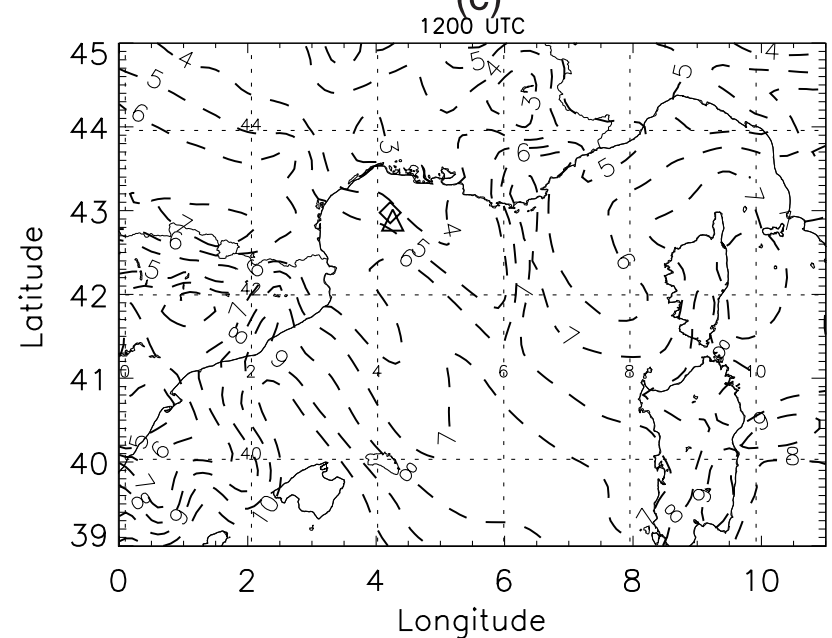

(e)

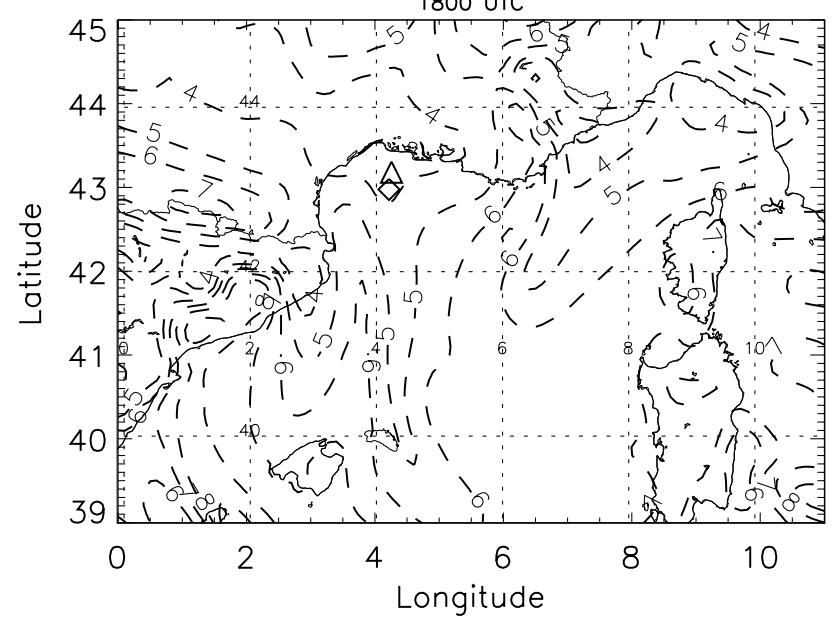

(b)

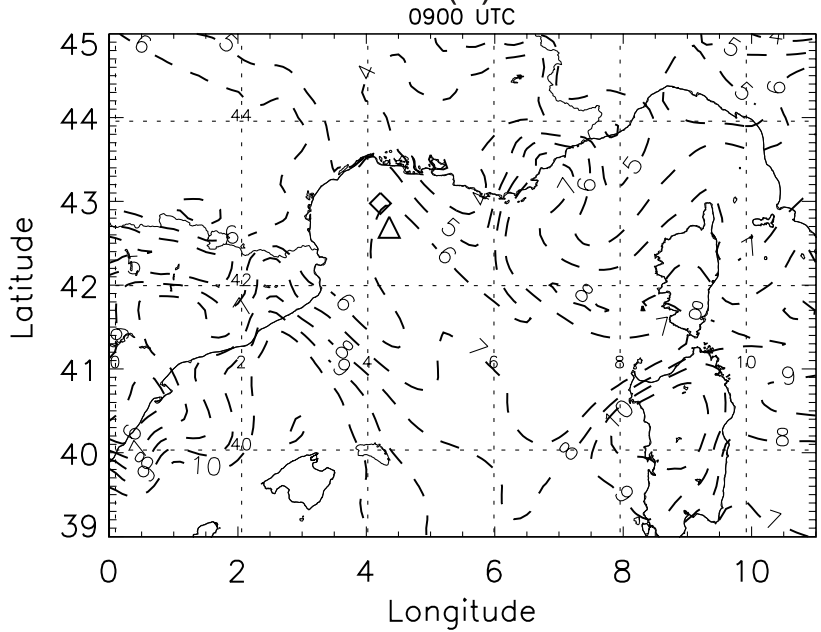

(d)

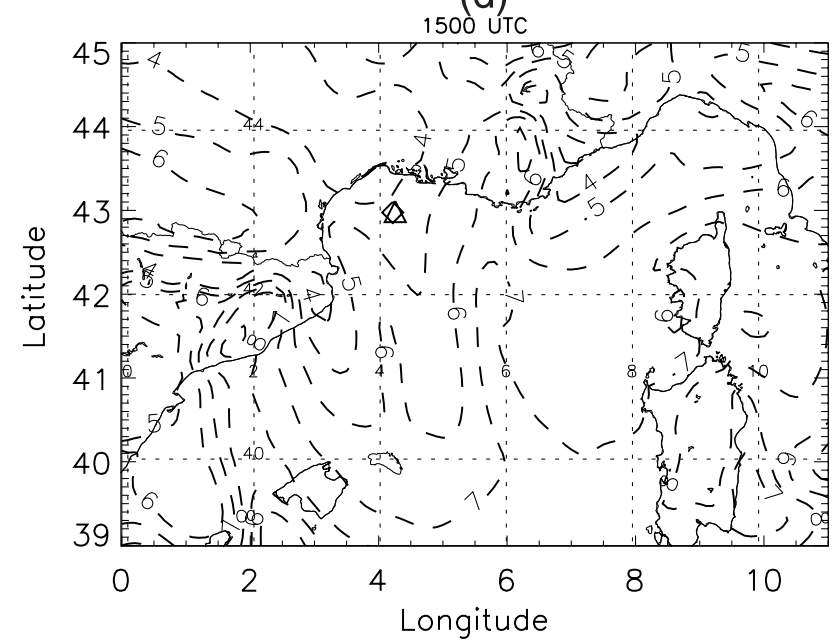

(f)

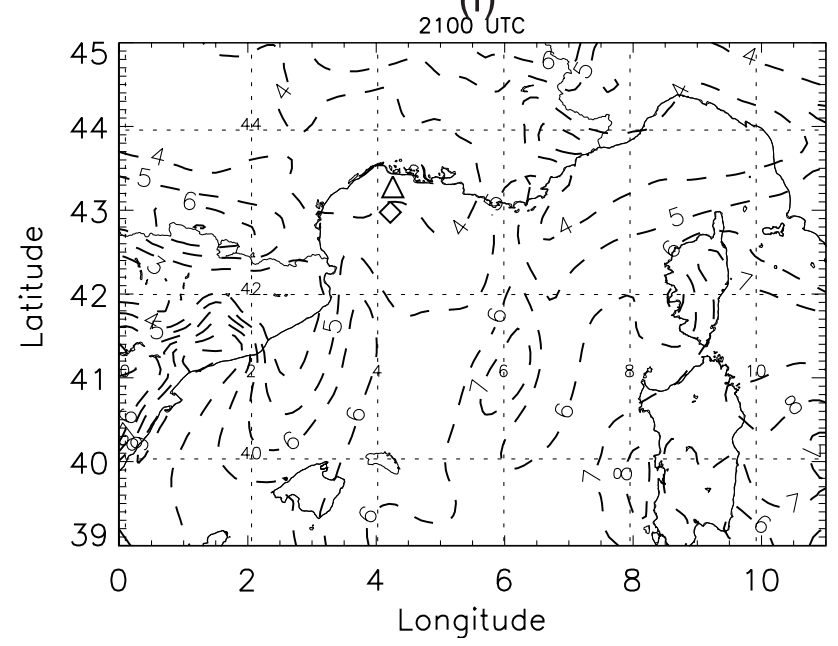

Figure 11. Same as Figure 6, but for the IWVC between the surface and $850 \mathrm{hPa}$.

derived distribution ( 0.22 versus 0.19 and 8 versus $9 \mathrm{~kg}$ $\mathrm{m}^{-2}$, respectively) are in good agreement given the precision of SSM/I estimates $\left(2-3 \mathrm{~kg} \mathrm{~m}^{-2}\right)$ and the uncertainty associated with ALADIN $( \pm 20 \%)$. The average IWVC values derived from the three distribution were approximately the same. The SSM/I-derived distribution was not observed to evolve significantly with time between 1642 and 1845 UTC. The ALADIN-derived distribution was found to be twice as broad as the SSM/I-derived distribution, which could be related to sensitivity and statistical issues. Indeed, the sample size of the 1642 and 1845 UTC SSM/I distributions was 74 
(a)

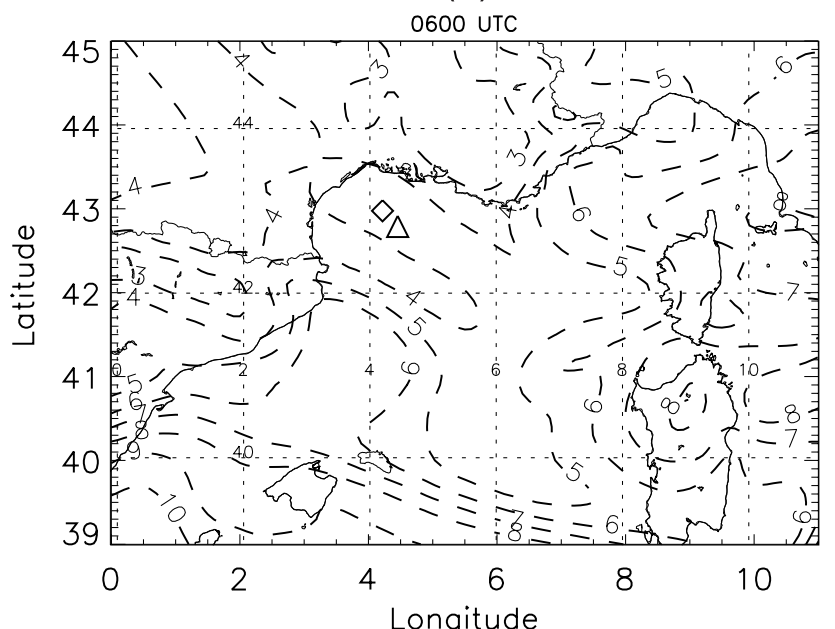

(c)

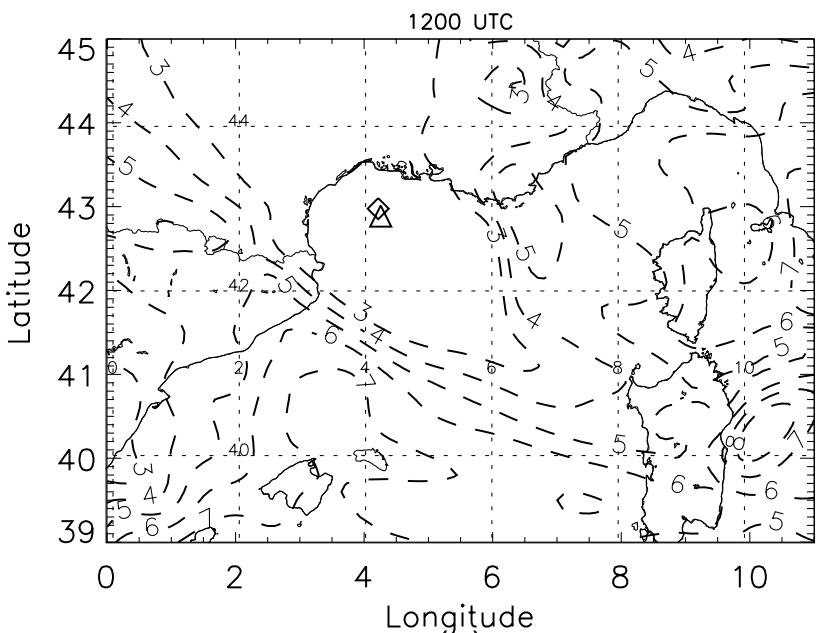

(e)

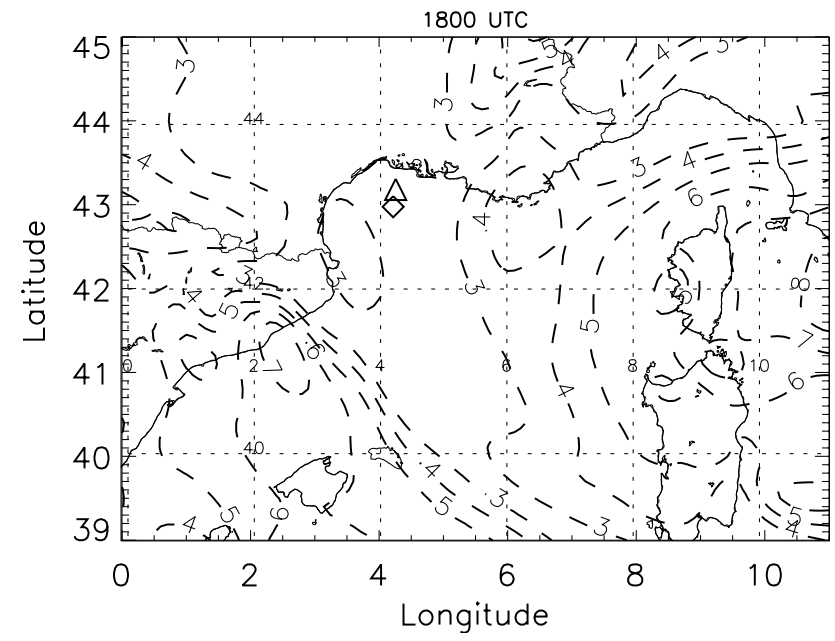

(b)

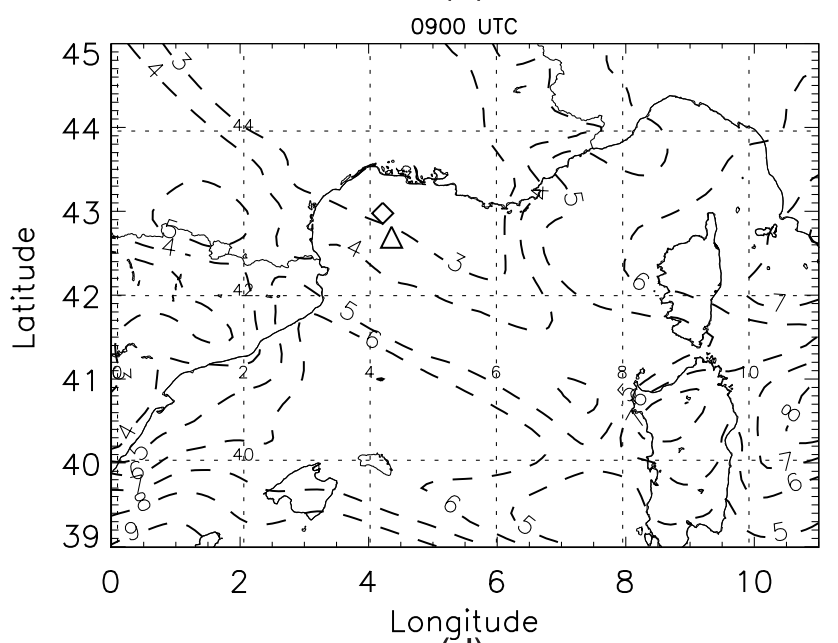

(d)

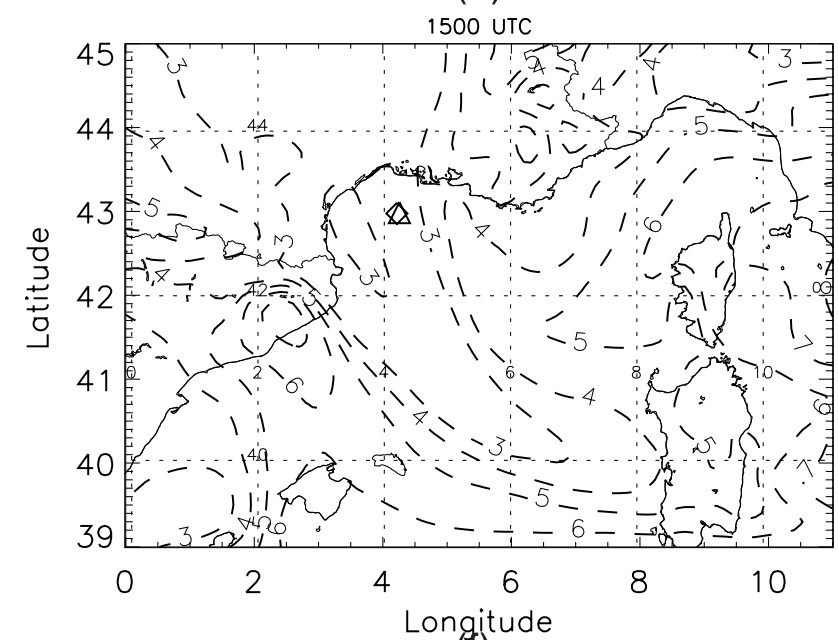

(f)

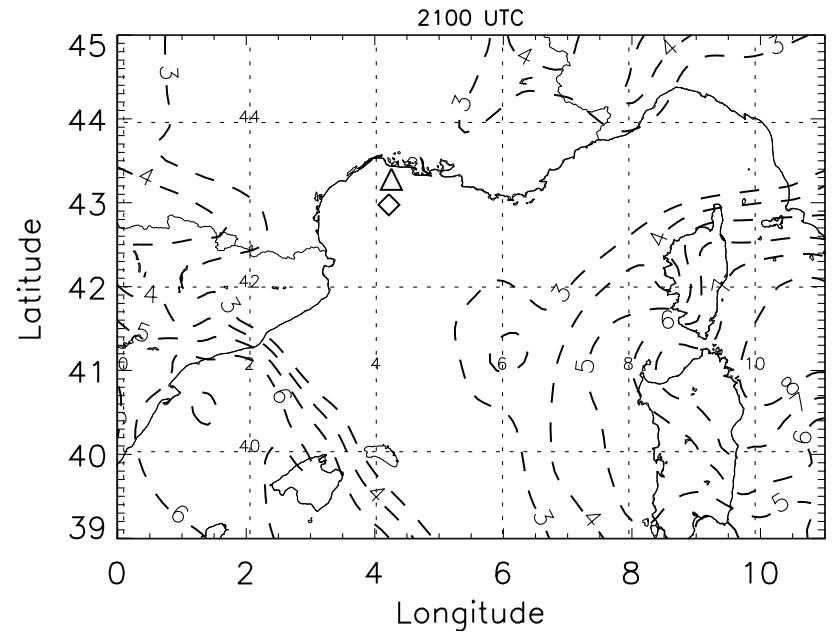

Figure 12. Same as Figure 6, but for the IWVC between 850 and $150 \mathrm{hPa}$. 


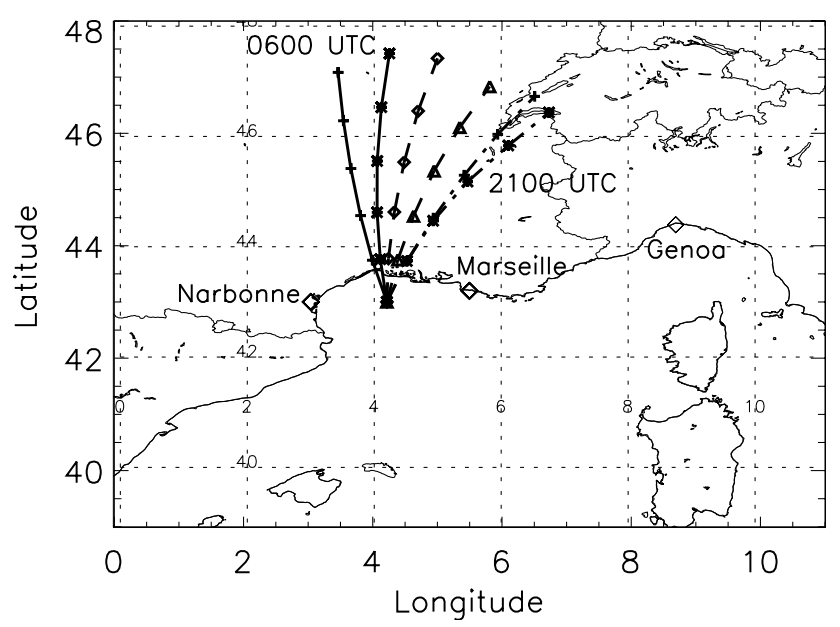

Figure 13. Twenty-four-hour isentropic back-trajectories ending at $3 \mathrm{~km}$ asl over the GoL on 24 March 1998 at 0600 UTC (solid line, crosses), 0900 UTC (solid line, asterisks), 1200 UTC (dotted line, diamonds), 1500 UTC (dotted line, triangles), 1800 UTC (dash-dotted line, crosses), and 2100 UTC (dash-dotted line, asterisks).

and 68 , respectively, while being equal to 1732 for the model-derived distribution.

\section{Multiplatform IWVC Estimates and Their Interpretation in the Meteorological Mesoscale Context}

5.1. Comparison of SSM/I-Derived and ALADINDerived IWVCs With Collocated Shipborne Microwave Radiometry: Temporal Evolution

[37] In Figure 15, we show the diurnal evolution of the IWVC estimated from DRAKKAR on 24 March 1998 superimposed with (1) the wind speed, (2) the RH, (3) the air temperature and SST, and (4) the latent heat fluxes measured simultaneously onboard the Atalante. Note that water vapor mixing ratio or WVC measured onboard the Atalante exhibited the same trends as RH and are not shown in the following. Mean and turbulent variables were obtained from an $12 \mathrm{~m}$ high instrumented mast located on the front deck of the ship (approximately $5 \mathrm{~m}$ asl). DRAKKAR was also sitting on the front deck, i.e., $12 \mathrm{~m}$ below the instruments on the mast. Latent heat fluxes are calculated using an inertial dissipation method (H. Dupuis et al., Impact of flow distortion corrections on turbulent fluxes estimated by the inertial-dissipation method during FETCH experiment on $\mathrm{R} / \mathrm{V}$ Atalante, submitted to Journal of Geophysical Research, 2002.). Four distinct time periods, classified as a function of their characteristic IWVC trends were identified:

1. 0000-0730 UTC: the northwesterly flow that prevailed over the GoL during this period lead to large IWVC values, in the range of $7.5-9.5 \mathrm{~kg} \mathrm{~m}^{-2}$ as observed by DRAKKAR. On average, the IWVC appeared to be (slightly) anticorrelated with all the other variables.

2. 0730-1000 UTC: large IWVC fluctuations were observed by DRAKKAR during that period. The IWVC first increased to values as large as $11 \mathrm{~kg} \mathrm{~m}^{-2}$, before decreasing to values as low as $5 \mathrm{~kg} \mathrm{~m}^{-2}$. These fluctuations were not connected to fluctuations of the SST as shown in
Figure 15c. In the Northern Hemisphere midlatitudes (SST $\leq 20^{\circ} \mathrm{C}$ ), the IWVC and the SST were shown to vary proportionally regardless of the season [Jackson and Stephens, 1995]. Thus, in our case, a $5-6^{\circ} \mathrm{C}$ SST variations would be needed to explain the behavior of the IWVC shown in Figure 15 if only ocean-related processes were controlling the air-sea moisture exchanges. As shown in Figure 16, the maximum value derived from DRAKKAR was not unrealistic since a similar value was derived from the 0900 UTC balloon sounding. This maximum coincided with a local maximum of $\mathrm{RH}$ and local minima of wind speed and air temperature which were interpreted by Flamant [2002] as being related to the advection over the Atalante of the sheltered region in the lee of the Massif Central, as the wind regime over the GoL shifted from prevailing Tramontane to prevailing Mistral. However, the corresponding increase of IWVC was not observed to be caused by such a feature (i.e., an drifting IWVC "banner" in the lee of the Massif Central) in Figure 6 or even Figure 11.

3. 1200 and 2030 UTC: the time periods when the Mistral blew (as evidenced by enhanced wind speed) (Figure 15a) corresponded to the periods where the IWVC measured by DRAKKAR was the smallest ( 5 and $4 \mathrm{~kg} \mathrm{~m}^{-2}$, respectively). The surface latent heat flux was maximum during these events (Figure 15d).

4. 1430-2000 UTC: this period was characterized by larger IWVCs (as much as $2 \mathrm{~kg} \mathrm{~m}^{-2}$ ) than during the Mistral events. This increase of IWVC was not correlated with an increase/decrease of any of the other variables. This could mean that a significant contribution to the IWVC was related to advection aloft the MABL, in connection with the outflow from the Ligurian Sea, as discussed in the previous section. Analyzing the evolution with time and height of the IWVC forecasted by ALADIN (not shown), revealed that (1) the surface latent heat flux was indeed correlated to the IWVC below $900 \mathrm{hPa}$ and (2) the larger IWVC values observed between 1500 and 1800 UTC in Figure 15 were caused by enhanced IWVCs above $700 \mathrm{hPa}$. Both of these results are illustrated in Table 3.

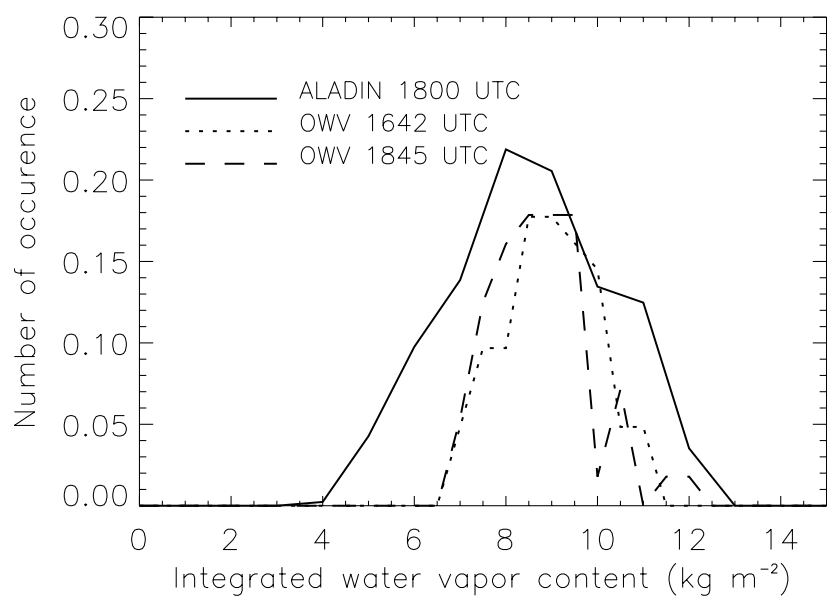

Figure 14. Histograms of IWVC distribution in a domain comprised between $3^{\circ} \mathrm{E}$ and $8^{\circ} \mathrm{E}$ and $40^{\circ}-44^{\circ} \mathrm{N}$ for OWV product extracted from DMSP F13 and F11 passages (1642 and 1845 UTC, dotted and dashed lines, respectively) and from ALADIN 1800 UTC forecast. 
(a)

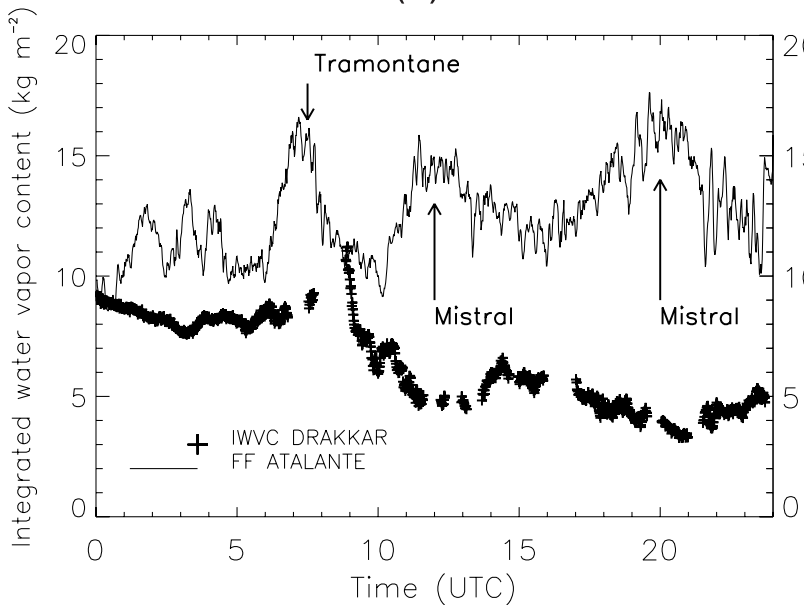

(c)

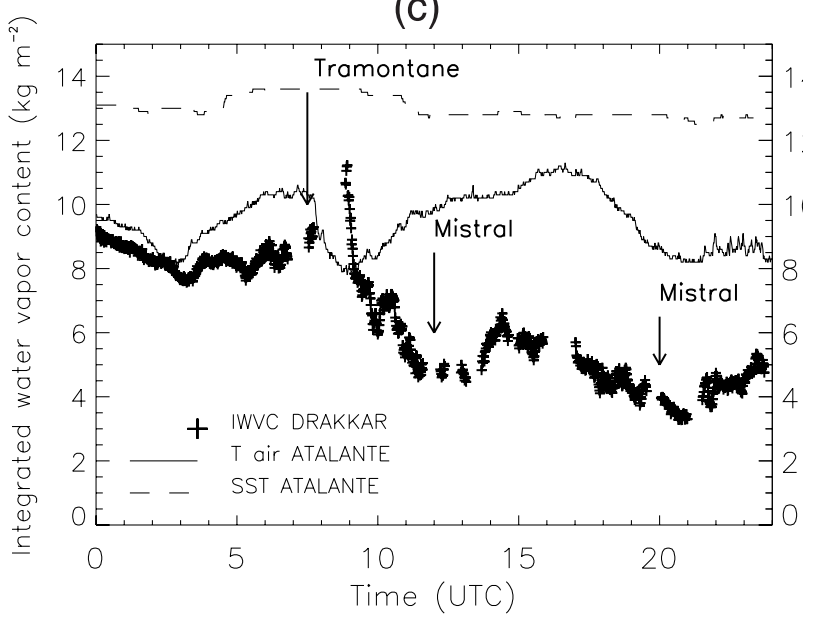

(b)

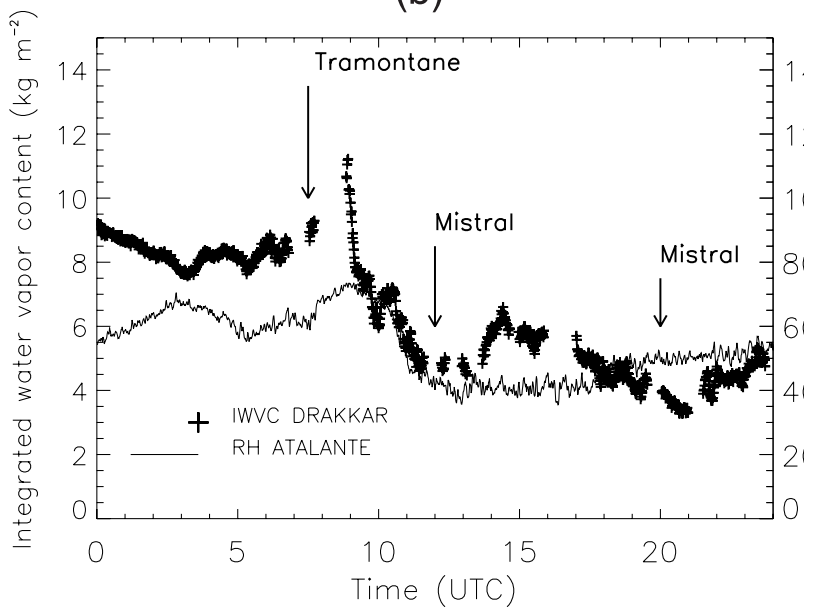

(d)

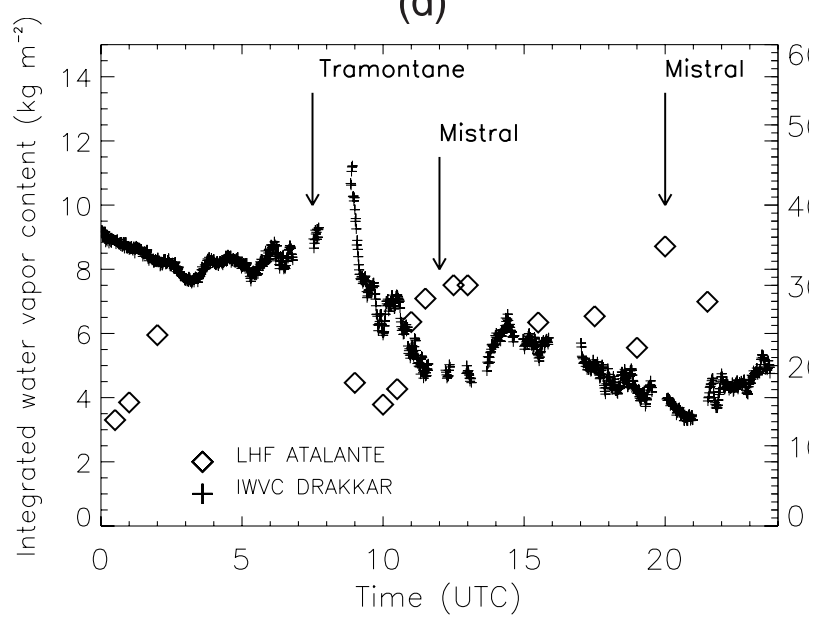

Figure 15. IWVC evolution on 24 March 1998 as estimated from DRAKKAR (+) onboard the Research Vessel Atalante over the GoL. Also superimposed to IWVC are wind speed (a), RH (b), air temperature (solid line) and SST (dotted line) (c), and latent heat fluxes (d) measurements made onboard the Research Vessel Atalante. "Tramontane" and "Mistral" refer to times when established Tramontane and Mistral regimes were observed over the GoL.

[38] In Figure 16, we have superimposed IWVC estimates from 3 balloon soundings, 2 LEANDRE 2 overpass of the Research Vessel Atalante, 4 SSM/I passages, and 6 ALADIN forecasts, on the diurnal evolution of the IWVC estimated from DRAKKAR on 24 March 1998. SSM/I and ALADIN IWVCs shown in Figure 16 corresponded to the pixel closest to the position of the ship at the time of the DMSP passages and the ALADIN forecasts. An excellent agreement was observed between the IWVC derived from the balloon soundings ( 3 launches at 0800,1200 , and 2400 UTC) and DRAKKAR. DRAKKAR and LEANDRE IWVCs were found in excellent agreement. The IWVCs obtained with SSM/I and ALADIN are almost always larger than their DRAKKAR counterpart.

[39] In the case of SSM/I, such overestimation has already been reported in coastal regions by Jackson and Stephens [1995], but their analysis did not account for errors introduced by land contamination. On the other hand, a bias-free agreement between radiosoundings and SSM/I retrievals was found by Bennartz [1999] when navigation uncertainty of SSM/I is corrected for. In the present case, even though we do use an elaborate correction algorithm such as that proposed by Bennartz [1999], the errors related to land contamination are not expected to be larger than 0.2 $\mathrm{kg} \mathrm{m}^{-2}$ (section 3.4). Yet, the bias observed in the afternoon (Figure 16) between SSM/I and DRAKKAR IWVC was larger than this value (i.e., $2 \mathrm{~kg} \mathrm{~m}^{-2}$ ). Rather, we believe that this bias is due to the fact that the sensitivity limit of the algorithm has been reached (recall the in the afternoon, dry conditions prevailed over the GoL). In the morning, when moister conditions prevailed, the agreement between SSM/I (one passage) and DRAKKAR was good. Finally, the fact that the SSM/I observations used in this study come from three different instruments (SSM/Is on F11, F13, and F14) cannot account for the differences observed between the morning and the afternoon because F11 flew during both period. Furthermore, the bias between the IWVC from different DMSP satellite (F10, F11, and F13) has been assessed in the framework of the Cloud Retrieval Validation Experiment (CLOREVAL) [Offiler et al., 1998]. It was shown that the largest bias was found for the $22 \mathrm{~V} \mathrm{GHz}$ channel (2.31 K between F10 and F13). For a sensitivity of 


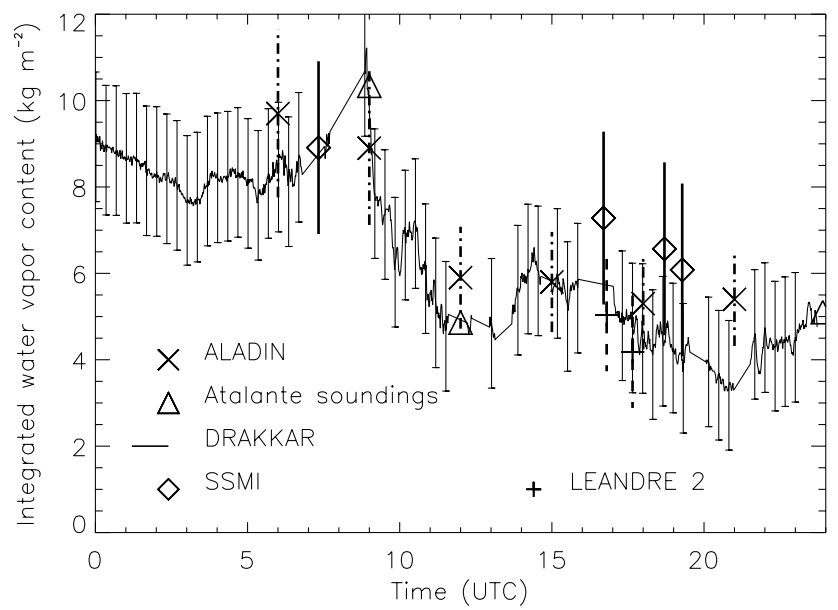

Figure 16. IWVC evolution on 24 March 1998 as estimated from DRAKKAR (solid line), ALADIN forecasts $(\times)$, LEANDRE 2 (crosses), and SSM/I OWV (diamonds). IWVC from ALADIN, LEANDRE 2, and SSM/I correspond to the pixel closest to the position of the ship. Also shown are the error bars taken as $\pm 2 \mathrm{~kg} \mathrm{~m}^{-2}, \pm 1.3 \mathrm{~kg} \mathrm{~m}^{-2}$, and $\pm 20 \%$ for SSM/I, LEANDRE 2, and ALADIN, respectively.

$1 \mathrm{~kg} \mathrm{~m}^{-2} \mathrm{~K}^{-1}$, the largest expected bias is on the order of $0.25 \mathrm{~kg} \mathrm{~m}^{-2}$. Note that the largest bias observed between F11 and F13 is $1.37 \mathrm{~K}\left(0.14 \mathrm{~kg} \mathrm{~m}^{-2}\right)$ for the $22 \mathrm{~V} \mathrm{GHz}$ channel. No similar information was available for F14 in the CLOREVAL final report, but biases are expected to be of the same order.

[40] Most importantly, the trend observed on the DRAKKAR data between 1430 and 2030 UTC (i.e., a decrease in IWVC) was well captured by SSM/I OWV product, despite the sensitivity issue, which is encouraging.

[41] In the case of ALADIN, IWVCs were indeed found to be larger in the morning than in the afternoon. However, ALADIN estimates did not exhibit a trend coherent with that derived from DRAKKAR. For example, in the afternoon, the ALADIN IWVC did not evolve much between 1200 and 2100 UTC (values ranged between 6.1 and $6.4 \mathrm{~kg}$ $\mathrm{m}^{-2}$ ) while DRAKKAR revealed significant fluctuation in that time period. The RMS deviation between ALADIN and DRAKKAR (even though not necessarily significant statistically, given the small number of samples) was less that the RMS deviation between SSM/I and DRAKKAR (1

Table 3. Total IWVC Estimated From ALADIN at the Location of the Research Vessel Atalante on 24 March $1998^{\mathrm{a}}$

\begin{tabular}{lcccc}
\hline & $\begin{array}{c}\text { Total } \\
\text { IWVC, }\end{array}$ & $\begin{array}{c}\text { IWVC } \\
\text { Below 900 hPa, } \\
\mathrm{kg} \mathrm{m}^{-2}\end{array}$ & $\begin{array}{c}\text { IWVC } \\
\text { Above } 800 \mathrm{hPa}, \\
\mathrm{kg} \mathrm{m}^{-2}\end{array}$ & $\begin{array}{c}\text { IWVC } \\
\text { Above } 700 \mathrm{hPa}, \\
\mathrm{kg} \mathrm{m}^{-2}\end{array}$ \\
\hline 0600, UTC UTC & 10.5 & 4.9 & 3.0 & 1.5 \\
0900 UTC & 9.5 & 4.7 & 2.1 & 0.7 \\
1200 UTC & 6.3 & 3.7 & 1.0 & 0.3 \\
1500 UTC & 6.4 & 3.4 & 1.5 & 0.6 \\
1800 UTC & 6.1 & 3.2 & 1.6 & 0.7 \\
2100 UTC & 6.1 & 3.5 & 1.5 & 0.7 \\
\hline
\end{tabular}

\footnotetext{
${ }^{\mathrm{a}}$ Also given are the IWVCs below $900 \mathrm{hPa}$, above $800 \mathrm{hPa}$, and above
} $700 \mathrm{hPa}$.

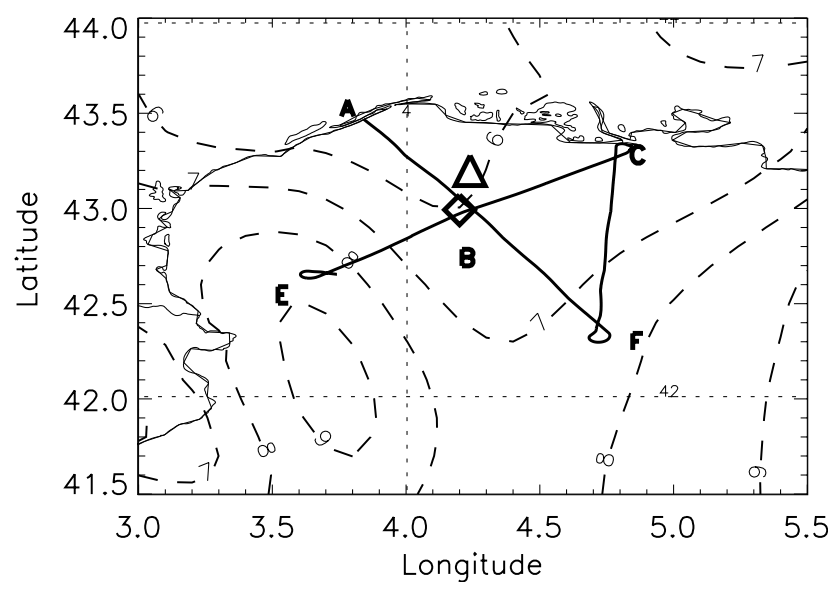

Figure 17. Same as Figure 6e, but zoomed over a smaller domain centered on the GoL and the afternoon ARAT flight track (solid line). The diamond and the triangle indicate the position of the ASIS buoy and of the Research Vessel Atalante (embarking DRAKKAR) at 1800 UTC, respectively. The ARAT flew the X-shaped pattern A-F-C-E between 1621 and 1728 UTC, with LEANDRE 2 pointing to the nadir.

versus $2.1 \mathrm{~kg} \mathrm{~m}^{-2}$ ). However, the trend of the time evolution of the IWVC was best captured by SSM/I.

[42] The overestimation of the IWVC derived from ALADIN, could be caused by the imperfect physics and (moisture) data assimilation, a problem inherent to all NWP models to this day [Gérard and Saunders, 1999; Gérard and Pailleux, 2000]. Bennartz [1999] also reported a positive bias between model results and both SSM/I and radiosoundings.

\subsection{Comparison of SSM/I-Derived and ALADIN-Derived IWVCs With Collocated Airborne Lidar Data: Spatial Distribution During the Period of Perturbed Mistral}

\subsubsection{ABL Structure}

[43] The structure of the ABL over the GoL during the disrupted Mistral period (1500-1800 UTC) has been investigated by means of airborne laser remote sensing measurements as well as aircraft and balloon in situ measurements. The flight track is shown in Figure 17. Lidar measurements show that in the region approximately east of $\approx 4.4^{\circ} \mathrm{E}$, the ABL depth decreased significantly $(0.7 \mathrm{~km}$ asl instead of 1.2 $\mathrm{km}$ asl to the west) [Flamant, 2002]. This region was affected by the outflow from the Ligurian Sea as discussed earlier. The large directional wind shear at the top of the Mistral ABL connected to the outflow from the Ligurian Sea was responsible for preventing the Mistral ABL from developing. This is illustrated by Figure 18 which shows the water vapor mixing ratio high resolution measurements (800 and $300 \mathrm{~m}$ on the horizontal and vertical, respectively) of tropospheric water vapor mixing ratio made by LEANDRE 2 over the GoL during F03. During this flight, the average lidar-derived water vapor mixing ratio in the lower $3 \mathrm{~km}$ asl were observed to be relatively small: less than $2 \mathrm{~g} \mathrm{~kg}^{-1}$ in the free troposphere and less than $5 \mathrm{~g} \mathrm{~kg}^{-1}$ in the MABL.

[44] Lidar measurements on leg AF (Figure 18a) evidenced an internal thermal boundary layer developing from 
(a)

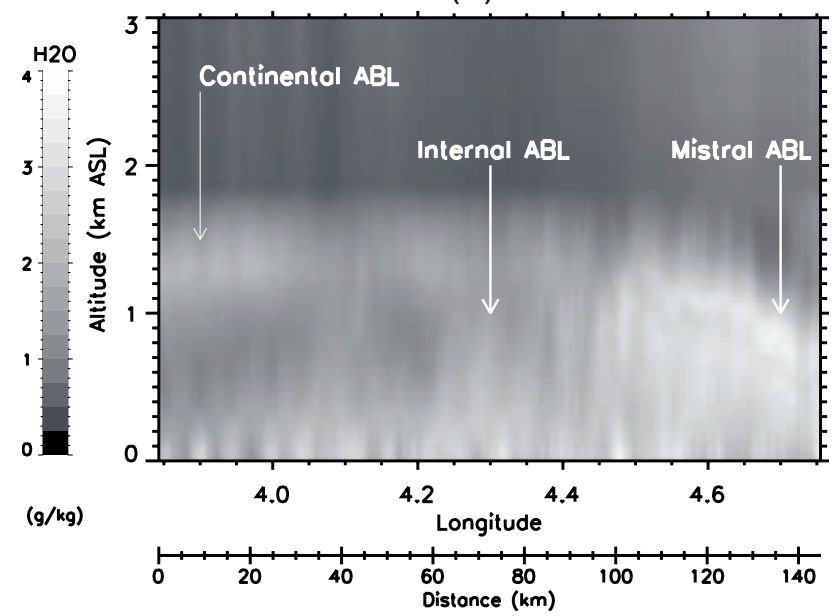

(b)

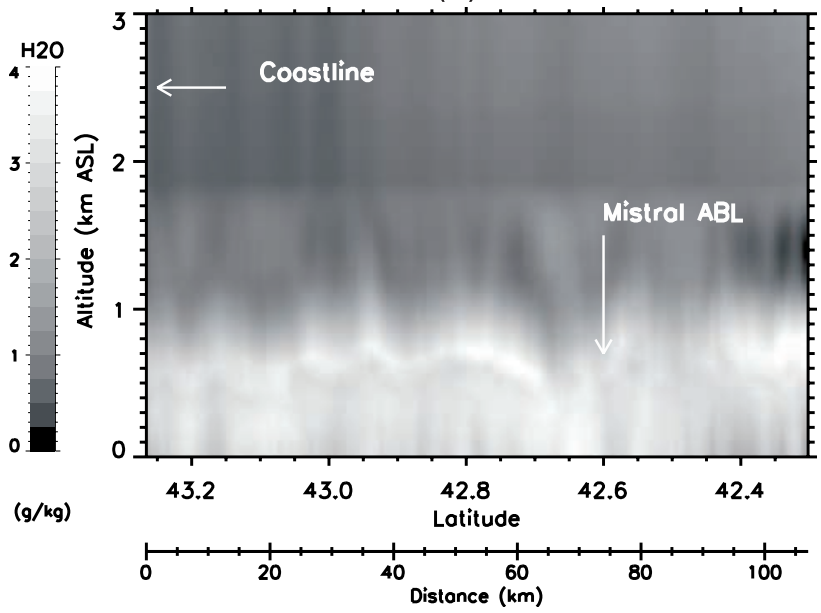

(c)

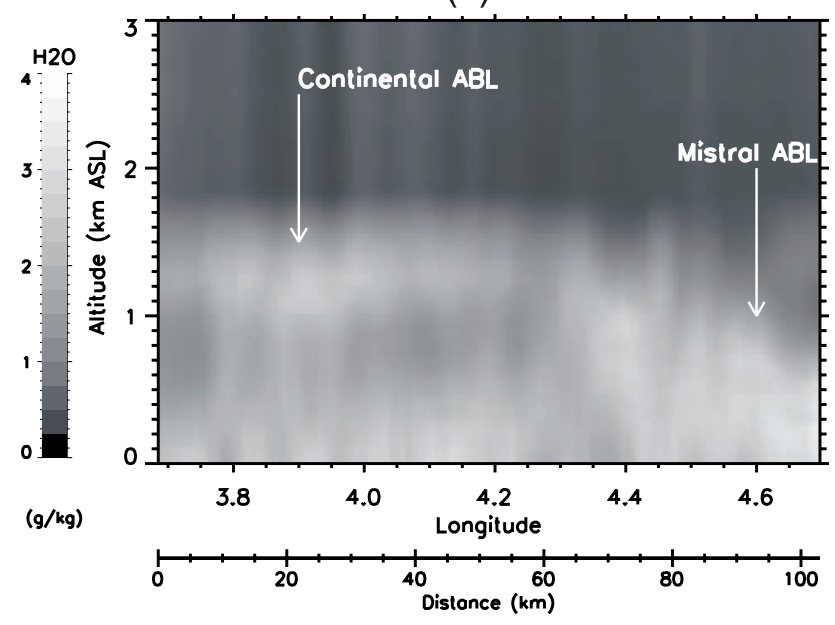

Figure 18. Water vapor mixing ratio as obtained from LEANDRE 2 along (a) leg AF (1621-1646 UTC), (b) leg FC (1648-1708 UTC), and (c) leg CE (1713-1728 UTC). See color version of this figure at back of this issue.

the coast (within the advected continental ABL) and reach a depth of $1200 \mathrm{~m}$. Closer to way-point $\mathrm{F}$, at approximately $4.4^{\circ} \mathrm{E}$, the MABL structure characteristics over the sea changed dramatically: it was observed to be shallower $(700 \mathrm{~m})$ (Figure $18 \mathrm{a}$ ) and was characterized by larger values of water vapor mixing ratio (approximately twice that observed to the west). This was confirmed by measurements made on leg FC (Figure 18b), along which the MABL was characterized by values of similar to those observed near way-point F. Also, the MABL was observed to remain shallow, its depth gradually increasing from 500 to $700 \mathrm{~m}$ with the distance to the coast. On leg CE (Figure 18c), close to the coast, the ABL structure was similar to that observed along FC (i.e., shallow). The depth of the MABL increased westward from 500 to $1000 \mathrm{~m}$ (between $4.7^{\circ} \mathrm{E}$ and $4.3^{\circ} \mathrm{E}$ ). Larger water vapor mixing ratio was observed to the east of $4.4^{\circ} \mathrm{E}$.

\subsubsection{IWVC}

[45] We now compare ALADIN IWVCs (1800 UTC) and SSM/I OWVs (1642 UTC) with LEANDRE 2 IWVC estimates along the ARAT flight track on leg AF (Figure 19a) and leg FC (Figure 19b). To do so, the closest grid point
(ALADIN) and observation point (SSM/I) to the ARAT flight track have been selected. Comparison with DRAKKAR estimates is also shown at the time when the aircraft overpassed the ship.

[46] In Figure 19a, the LEANDRE 2-derived IWVC was observed to increase from 4.5 to $6.5 \mathrm{~kg} \mathrm{~m}^{-2}$ between waypoints $\mathrm{A}$ and $\mathrm{F}$, in connection with the increase of lidarderived water vapor mixing ratio observed in Figure 18. This increase was in agreement with that seen in Figure 17 along the aircraft track and was also observed on the SSM/I OWV series. The agreement between LEANDRE IWVC and SSM/I OWV was best in the region characterized by larger IWVCs most likely because of sensitivity issues. Along leg FC (in the moister region) (Figure 19b), the lidar, ALADIN, and SSM/I IWVC estimates fluctuated around mean values of $5.9,6.6$, and $8.9 \mathrm{~kg} \mathrm{~m}^{-2}$. The RMS deviation between SSM/I and LEANDRE 2 was equal to $3.4 \mathrm{~kg} \mathrm{~m}^{-2}$ in the drier Mistral region and equal to $3 \mathrm{~kg} \mathrm{~m}^{-2}$ in the moister region. The agreement between LEANDRE 2 and ALADIN IWVCs was good, the RMS deviation being equal to $0.85 \mathrm{~kg} \mathrm{~m}^{-2}$ in the unperturbed (driest) Mistral region and equal to $0.75 \mathrm{~kg} \mathrm{~m}^{-2}$ in the region perturbed by 
(a)

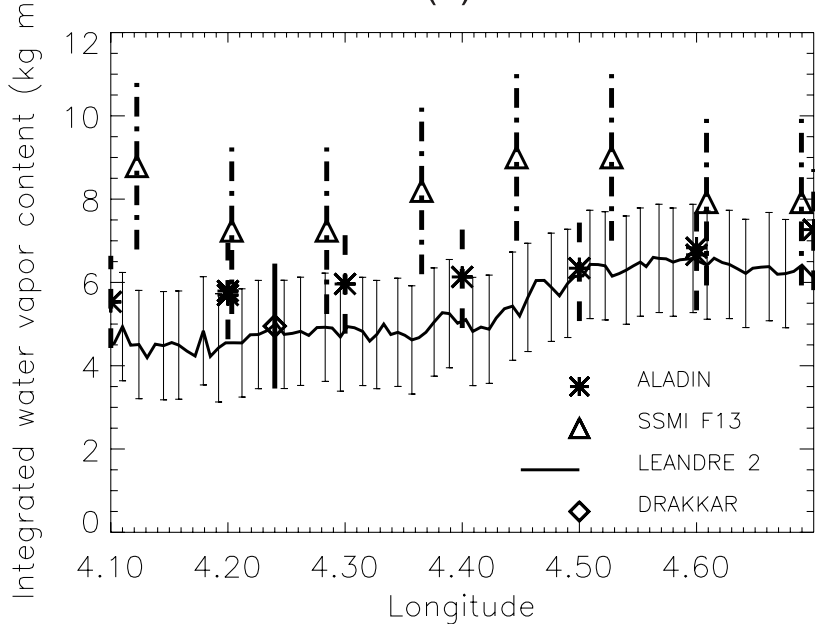

(b)

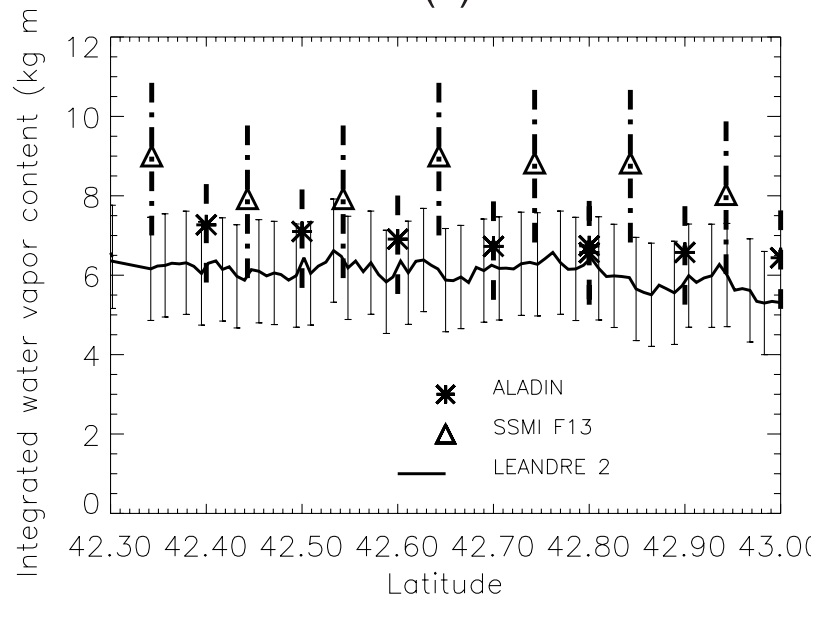

Figure 19. IWVC from LEANDRE 2 (solid line) along (a) leg AF (1620-1645 UTC) and (b) leg FC (1646-1708 UTC). Superimposed are SSM/I OWVs at 1642 UTC (triangles), ALADIN IWVC (asterisks) and DRAKKAR IWVC at 1600 UTC (diamond, on leg AF only). Error bars correspond to $\pm 2 \mathrm{~kg} \mathrm{~m}^{-2}, \pm 1.3 \mathrm{~kg} \mathrm{~m}^{-2}$, and $\pm 20 \%$ for SSM/I, LEANDRE 2 , and ALADIN, respectively.

the return flow of the Tyrrhenian cyclone. Finally, DRAKKAR and LEANDRE IWVCs were found in good agreement on the single comparison point available.

\section{Summary and Conclusion}

[47] The representativity of SSM/I and ALADIN IWVC estimates in a coastal region have been investigated during nonstationary cold-air outbreak conditions on 24 March 1998. The nonstationary nature of the wind regime over the GoL was controlled by the multistage evolution of an Alpine lee cyclone over the Tyrrhenian Sea (between Sardinia and continental Italy). In the early stage, large IWVCs (between 8 and $10 \mathrm{~kg} \mathrm{~m}^{-2}$ ) were observed over the GoL in connection with a prevailing Tramontane regime. As the low deepened, the prevailing wind regime shifted to a well established Mistral. The time period when the Mistral blew (i.e., from 1200 to 2100 UTC) was characterized by lower IWVCs (between 3 and $6.5 \mathrm{~kg} \mathrm{~m}^{-2}$ ). Within this period (i.e., from 1500 to 1800 UTC), the eastern part of Mistral flow was progressively disrupted by a strengthening outflow from the Ligurian Sea in connection with a deepening depression located over the Tyrrhenian Sea (between Sardinia and continental Italy). During this period, an increase of the IWVC, by as much as $2 \mathrm{~kg} \mathrm{~m}^{-2}$, was observed by DRAKKAR over the GoL. Using LEANDRE 2 water vapor mixing ratio and shipborne in situ measurements as well as ALADIN, it was shown that this increase was related to an increase of the IWVC in both the MABL and aloft. In the MABL, the IWVC distribution over the GoL was controlled by the thermodynamics of the Tramontane and Mistral flows. Aloft, the thermodynamics processes occurring in the lee of the Alps seemed to have a nonnegligible influence on the IWVC distribution.

[48] Comparisons SSM/I and ALADIN IWVCs with collocated shipborne microwave radiometry were carried out on a full diurnal cycle. SSM/I products yielded a RMS deviation of $2.1 \mathrm{~kg} \mathrm{~m}^{-2}$ while ALADIN outputs yielded a
RMS deviation of $1 \mathrm{~kg} \mathrm{~m}^{-2}$. The RMS between SSM/I estimates and DRAKKAR measurements was found to be slightly smaller than that assessed in coastal regions using soundings (i.e., $2.5 \mathrm{~kg} \mathrm{~m}^{-2}$ ) [Bennartz, 1999]. Comparisons of SSM/I and ALADIN IWVC estimates with collocated airborne lidar measurements were also carried out to analyze the spatial evolution of the IWVC in the period of perturbed Mistral. The RMS deviation between SSM/I and LEANDRE 2 was equal to $3.4 \mathrm{~kg} \mathrm{~m}^{-2}$ in the drier Mistral region and equal to $3 \mathrm{~kg} \mathrm{~m}^{-2}$ in the moister region. These RMS errors were assessed during one of the driest time period analyzed. The ALADIN-related RMS deviation was equal to $0.85 \mathrm{~kg} \mathrm{~m}^{-2}$ in the drier Mistral region and equal to $0.75 \mathrm{~kg} \mathrm{~m}^{-2}$ in the region perturbed by the return flow of the Tyrrhenian cyclone.

[49] Nevertheless, the trends of the temporal and spatial evolutions of IWVC were well captured by SSM/I, more so than those exhibited by ALADIN. Compared to DRAKKAR, ALADIN and SSM/I overestimates the IWVC. Nevertheless, even in dry conditions and in coastal zones, the temporal and spatial evolution trends of IWVC were well captured by SSM/I. During the dry period, SSM/I estimates were found to be systematically larger than their DRAKKAR and LEANDRE counterparts. This could be related to the sensitivity limit of SSM/I and the associated large uncertainties. Another explanation could be that Petty's algorithm is tuned and validated in open ocean conditions and has not been validated in coastal regions. Furthermore, there may also be evidence of the impact of sea state on the IWVC retrievals. Different behavior have been observed in increasing and decreasing wind conditions. Further investigations should be conducted on the role of sea state on the IWVC retrievals in coastal regions.

[50] Acknowledgments. The authors would like to thank Danile Hauser, who coordinated the FETCH experiment, and their colleagues who have participated in the FETCH for acquiring, processing, and providing the data as well as for helpful discussions. They are indebted to Hlne Dupuis for providing the shipborne turbulent heat fluxes. Special 
thanks to Didier Bruneau, Vincent Trouillet, and Pascal Genau of Service d'Aéronomie and Frederic Blouzon, Abdel Abchiche, Nadir Amarouche, Guy Pennazzi, Christian Allet, Noël Grand, André Gribkoff, and Bernard Sinardet of the Technical Division (INSU). This research was funded by INSU/CNRS via the PATOM and PNTS programs. Many thanks to Ralf Bennartz (Institut für Weltraumwissenschaften) and to two anonymous reviewers for comments and suggestions that led to a significant improvement of this paper.

\section{References}

Alishouse, J., S. Snyder, J. Vongsathorn, and R. Ferraro, Determination of total precipitable water from the SSM/I, IEEE Trans. Geosci. Remote Sens., 28, 811-816, 1990.

Bennartz, R., On the use of SSM/I measurements in coastal regions, J. Atmos. Oceanic Technol., 16, 417-431, 1999.

Boukabara, S. A., Couplage des mesures hyperfrequences actives et passives, Thse de Doctorat, 261 pp., Univ. Paris VII, Paris, 1997. (available from CETP/IPSL/CNRS)

Bruneau, D., P. Quaglia, C. Flamant, M. Meissonnier, and J. Pelon, The airborne lidar LEANDRE 2 for water vapor profiling in the troposphere, part 1, Description, Appl. Opt., 40, 3450-3461, 2001a.

Bruneau, D., P. Quaglia, C. Flamant, and J. Pelo, The airborne lidar LEANDRE 2 for water vapor profiling in the troposphere, part 2, First results, Appl. Opt., 40, 3462-3475, 2001b.

Campins, J., A. Genoves, A. Jansa, J. A. Guijarro, and C. Ramis, A catalogue and a classification of surface cyclones for the western Mediterranean, Int. J. Climatol., 20, 969-984, 2000.

England, M. N., F. J. Schmidlin, and J. M. Johansson, Atmospheric moisture measurements: A microwave radiometer-radiosonde comparison, IEEE Trans. Geosci. Remote Sens., 31, 389-398, 1993.

Eymard, L., Analysis of cloud liquid water content characteristics from SSMI and a shipborne radiometer, in Microwave Radiometry and Remote Sensing of the Earth's Surface and Atmosphere, edited by P. Pampaloni and S. Paloscia, pp. 235-245, VSP Int. Sci., Tokyo, 2000.

Eymard, L., A. Weill, D. Bourras, C. Guerin, P. Le Borgne, and J.-M. Lefevre, Use of ship mean data for validating model and satellite flux fields during the FETCH experiment, J. Geophys. Res., 108, doi:10.1029/ 2001JC001207, in press, 2003.

Flamant, C., Alpine lee cyclogenesis influence on air-sea heat exchanges and marine atmospheric boundary layer thermodynamics over the western Mediterranean during a Tramontane/Mistral event, J. Geophys. Res., 107, doi:10.1029/2001JC001040, in press, 2002.

Fleming, R., A note on temperature and relative humidity corrections for humidity sensors, J. Atmos. Oceanic Technol., 15, 511-515, 1998.

Gérard, E., and R. W. Saunders, 4DVAR assimilation of SSM/I total column water vapor in the ECMWF model, Q. J. R. Meteorol. Soc., 125 3077-3101, 1999.

Gérard, E., and J. Pailleux, Role of water vapour in numerical weather prediction models, in Advances in Laser Remote Sensing, selected papers of the 20th International Laser Radar Conference, edited by A. Dabas et al., pp. 285-288, Ed. de l'École Polytech., Palaiseau, 2000.

Goodberlet, M., and C. T. Swift, DMSP SSM/I sensor description and calibration, in NASA Sea Ice Validation Program for the Defense Meteorological Satellite Program Special Microwave Imager: Final Report, NASA Tech. Memo. 104559, edited by D. J. Cavalieri, NASA, Goddard Space Flight Cent., Greenbelt, Md., 1992.
Hauser, D., H. Dupuis, X. Durrieu de Madron, C. Estournel, C. Flamant, J. Pelon, and P. Queffelou, La campagne FETCH: Une expérience pour l'étude des échanges océan/atmosphère dans les conditions côtières du Golfe du Lion, Météorologie, 29, 14-31, 2000.

Hauser, D., et al., The FETCH experiment: An overview, J. Geophys. Res., 107, doi:10.1029/2001JD001202, in press, 2002. [printed 108(3), 2003]

Helten, M., H. Smit, W. Stäter, D. Kley, P. Nedelec, M. Zöger, and R. Busen, Calibration and performance of automatic compact instrumentation for the measurement of relative humidity from passenger aircraft, J. Geophys. Res., 103, 25,643-25,652, 1998.

Jackson, D. L., and G. L. Stephens, A study of SSM/I-derived columnar water vapor over the global ocean, J. Clim., 8, 2025-2038, 1995.

Katsaros, K. B., and R. A. Brown, Legacy of the Seasat mission for studies of the atmosphere and air-sea-ice interactions, Bull. Am. Meteorol. Soc., 72, 967-981, 1991

Louis, J.-F., M. Tiedtke, and J.-F. Geleyn, A short history of the operational PBL-parameterization at ECMWF, in ECMWF Workshop Proceedings on "Planetary Boundary Layer Parameterization", pp. 5979, Eur. Cent. for Medium-Range Weather Forecasts, Reading, U.K., 1981.

Offiler, D., L. Eymard, D. Kilham, E. Gérard, and H. Gäng, Cloud Retrieval Validation Experiment (CLOREVAL), Final Report, 72 pp., September 1998. (available from D. Offiler at UKMO)

Petty, G. W., SSMI/algorithms for the estimation of column water vapor, in Proceedings of the Shared Processing Network DMSP Special Microwave Imager Symposium, Fleet Numer. Oceanogr. Cent., Monterey, Calif., 1993. (available from FNMOC)

Schlüssel, P., and W. E. Emery, Atmospheric water-vapor over the ocean from Special Sensor Microwave/Imager observations, Int. J. Remote Sens., 11, 753-766, 1990.

Stephens, G. L., On the relationship between water vapor over the ocean and sea surface temperature, J. Clim., 3, 1779-1800, 1990.

Special Sensor Microwave/Imager (SSM/I), User's interpretation guide, 4th ed., Dept. of the Air Force, Space and Missile Syst. Cent., 1999. (available at http://www.moc.navy.mil/PUBLIC/SATELLITE/TUTORIAL/ ssmi.pdf)

Trigo, I. F., T. D. Davies, and G. R. Bigg, Objective climatology of cyclones in the Mediterranean region, J. Clim., 12, 1685-1696, 1999.

Vesperini, M., F.-M. Béron, and D. Tanrć, Atmospheric water vapor content from spaceborne POLDER measurements, IEEE Trans. Geosci. Remote Sens., 37, 1613-1619, 1999.

L. Eymard, Centre d'Etude des Environnements Terrestre et Planétaires (CETP)/IPSL, Centre National de la Recherche Scientifique (CNRS), Université St Quentin-Versailles, 10-12 avenue de l'Europe, F-78140 Vélizy, France. (Laurence.Eymard@cetp.ipsl.fr)

C. Flamant and J. Pelon, Service d'Aéronomie/IPSL, Université Pierre et Marie Curie, Boîte 102, 4 place Jussieu, F-75252 Paris, France. (cyf@aero.jussieu.fr; jpe@aero.jussieu.fr)

J. Tournadre, Département d'Océanographie Spatiale DRO/OS, Institut Français de Recherche pour l'Exploitation de la Mer (IFREMER), BP 70 , F-29280 Brest, France. (Jean.Tournadre@ifremer.fr) 
(a)

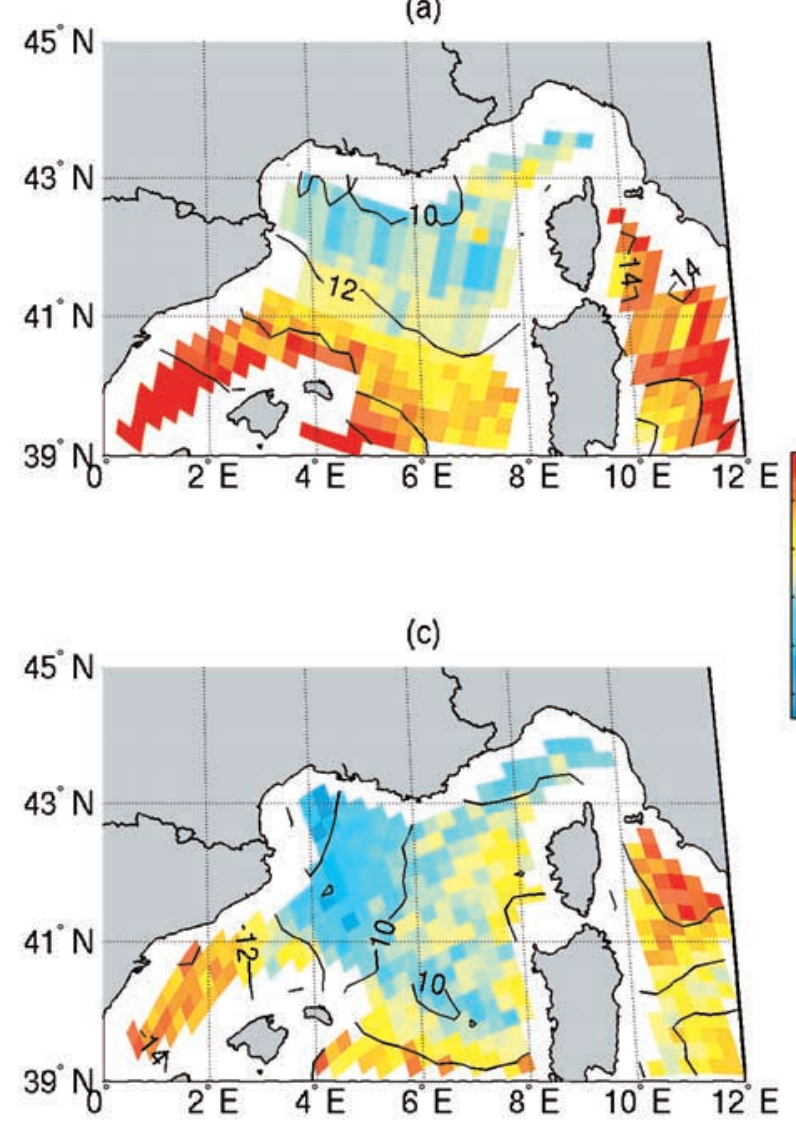

(b)

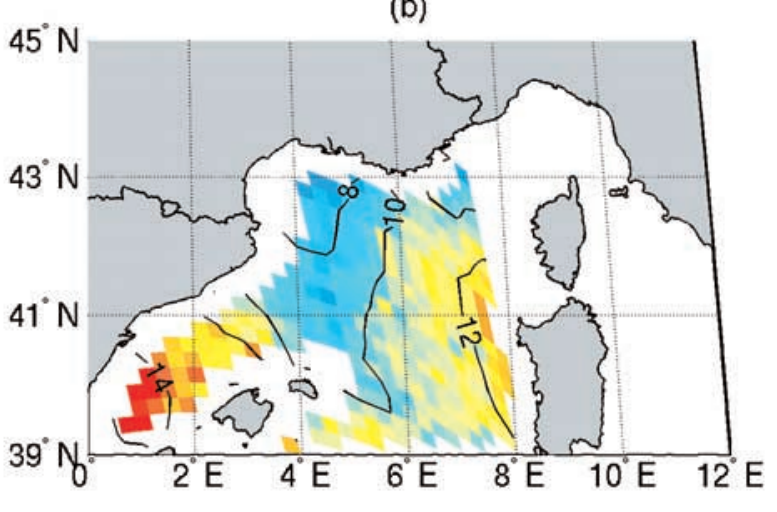

(d)

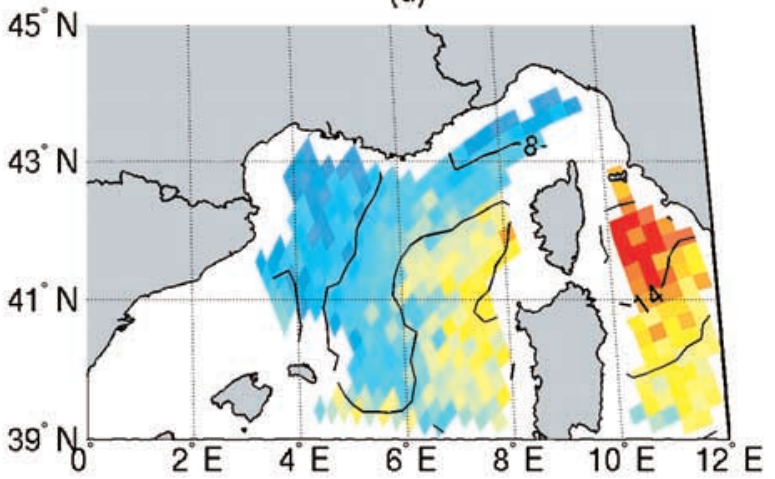

Figure 7. IWVC estimated from DMSP/SSM/I platforms using Petty's OWV algorithm: F11 at 0720 UTC (a), F13 at 1642 UTC (b), F11 at 1845 UTC (c), and F14 at 1917 UTC (d). Superimposed are isoIWVC between 2 and $16 \mathrm{~kg} \mathrm{~m}^{-2}$ with $2 \mathrm{~kg} \mathrm{~m}^{-2}$ increments. 
(a)

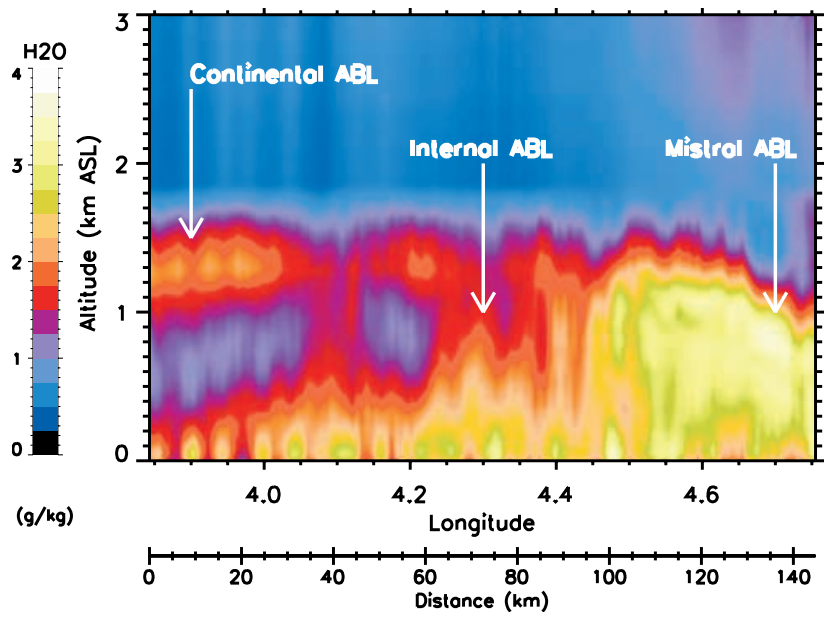

(b)

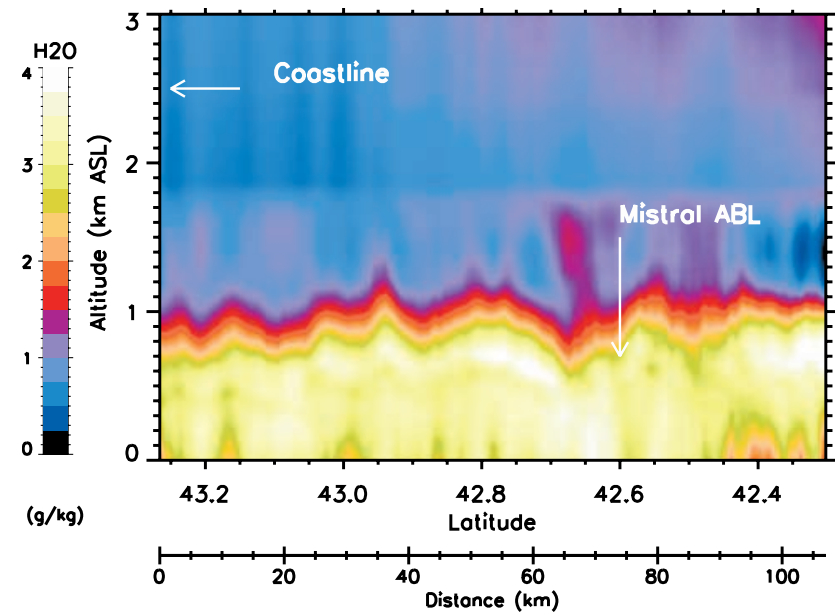

(c)

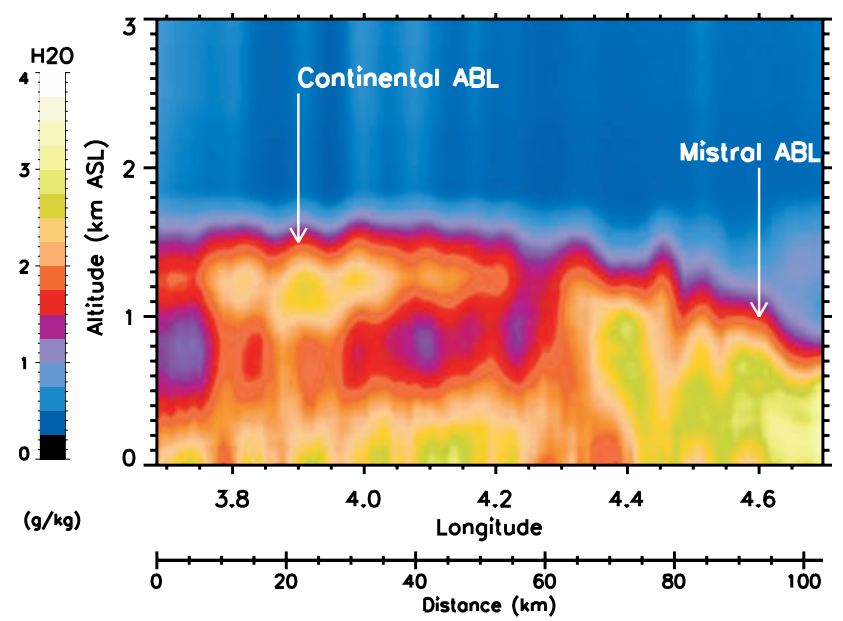

Figure 18. Water vapor mixing ratio as obtained from LEANDRE 2 along (a) leg AF (1621-1646 UTC), (b) leg FC (1648-1708 UTC), and (c) leg CE (1713-1728 UTC). 